\title{
XXXIV.
}

\section{Ein Beitrag zum Studium der Dissociation der Temperatur- und Schmerzempfindung bei Ver- letzungen und Erkrankungen des Ruickenmarkes.}

\author{
Von \\ Dr. med. J. Piltz, \\ Professor der Psychiatrie und Nervenheilkunde an der Universität in Krakaul, gew. Primararzt \\ der Nervenabtheilung am städtischen Praga-Hospital in Warschau.
}

(Mit 16 Abbildungen.)

Literatur.

Die sogenannte "syringonyelitische Dissociation" der Sensibilität, d. h. ein Schwund der Temperatur- und Schmerzempfindung bei gut erhaltener taktiler Sensibilität, wird beobachtet: 1 . bei Erkrankungen des Grosshirns, 2. der peripherischen Nerven und 3. des Rückenmarkes.

Ad 1. Chatin beobachtete bei cerebraler Hemiplegie eine Verminderung der Wärmeempfindung und Verlangsamung der Wärmeleitung bei gut erhaltener Kälteempfindung. Manchmal hat er auch constatiren können, dass in solchen Fällen Wärme als Kälte empfunden wurde. Analoge Beobachtungen wurden vorher auch schon von Long gemacht. Oppenheim constatirte einige Male Beeinträchtigung des Schmerz- und Temperaturgefühls bei Läsion des hinteren Bezirkes der inneren Kapsel. Rossolimo und Bálint beschrieben Thermoanaesthesie und Aualgesie bei Affectionen des Hirustammes. ${ }^{1}$ )

Ad 2. Schon Nothnagel sprach davon, dass die Dissociation der Sensibilität eventuell auch als Folge einer peripherischen Nervenentzündung auftreten kann. J. B. Charcot beschrieb Analgesie und Ther-

1) Liepmann beobachtete bei cerebraler Hemiplegie einen Schnund der "tiefen Schmerzempfindung" (im Gegensatz zur „oberflächlichen“). 
moanaesthesie bei Compression eines peripherischen Nerven; van Gehuchten und Teljatnik beobachteten dieses Phänomen bei Neuritis, Ferrari bei traumatischer Verletzung eines peripherischen Nerven und Biernacki bei der sngenannten Drucklähmung peripherischer Nerven.

Ad 3. Die Dissociation der Sensibilität kommt vor bei der Syringomyelie; sie ist aber für diese Krankheit durchaus nicht pathognomonisch, da sie auch bei anderen Krankheiten des Rückenmarkes verhältnissmässig oft beobachtet wird: Brown-Séquard, Hoffmann, Gowers, Sottas, Rheinhardt, Mann, v. Reusz, H. Llyod, Crocq, Kopczynski, Petrén, Schlittenhelm, Fürnrohr u. A. beschrieben Fälle von einseitiger Verletzung des Rückenmarkes mit gekreuzter Analgesie und Thermoanaesthesie bei erhaltener oder nur verminderter Tastempfindung und Mann hat auf Grund seiner eigenen Erfahrung und der gesamme!ten Litteratur speciell darauf hingewiesen, dass das Vorkommen der sogenannten "syringomyelitischen Dissociation" der Sensibilität in Fällen von Brown-Séquard'scher Lähmung zur Regel gehört. Herzen beobachtete in einem Fall von Pachymeningitis hypertrophica, neben anderen Symptomen, vollständigen Verlust der taktilen Sensibilität und dor Kälteempfindung bei erhaltener Schmerz- und Wärmeempfindung; Wallenberg und Mai sahen die Dissociation der Sensibilität nach einem apoplektischen Insult in das verlängerte Mark auftreten. Minor, Bregmann, Pribytkoff und Versiloff bei traumatischer Hämatomyelie; Sklodowski bei vermuthlicher Hämorrhagie oder Thrombose der grauen Substanz des Rückenmarkes; Higier bei Haematomyelie des Conus medullaris. Bruns und Schlesinger beschreiben die syringomyelitische Störung der Sensibilität bei Tumoren des Rückenmarkes; E. Flatau und Koelichen beobachteten in einem Fall von Mediastinaltumor, der in der Höhe des dritten bis siebenten Dorsalwirbels durch die Foramina intervertebralia bis auf die Meningen des Rückenmarkes durchgedrungen ist, neben einer Paraplegie, vollständigen Schwund des Wärmegefühls auf dem Abdomen, unterhalb des Rippenrandes, und auf den unteren Extremitäten. Die Tast- und und Schmerzempfindung war dort nur etwas herabgesetzt, dagegen auf den Unterschenkeln und Füssen ganz aufgehoben. Lähr, Hanoई und Meunier beobachteten die Dissociation der Sensibilität bei Gummaten des Rückenmarkes, Brissaud und Raymond bei spinaler Syphilis, Dejerine und Thomas bei Meningomyelitis syphilitca, Van Gehuchten, Edsall, Marinesco und Vines bei Compression des Rückenmarkes, Pick bei Myelitis. 
In Bezug auf die Topographie der allgemeinen spinalen Anästhesie haben bereits schon Ross, Allen Starr, Sherrington, Thorbarn u. A. darauf hingewiesen, dass die taktile spinale Anästhesie sich von der peripherischen und cerebralen Anästhesie durch die Art ihrer Ausbreitung auf der Haut wesentlich unterscheidet, so dass man aus der Topographie der Sensibilitätsstörung schliessen kann, ob die beobachtete Sensibilitätsstörung durch eine Erkrankung des Rückenmarkes bedingt ist oder nicht, und mit einer gewissen Sicherheit sogar den Sitz der Erkrankung des Rückenmarkes bestimmen kann.

Die Topographie der spinalen Analgesie und Thermoanästhesie ist in der Regel auch wie die Topograpbie der spinalen Anästhesie eine radiculäre und aus der Art ihrer Ausbreitung können auch, wie wir unten sehen werden, in Bezug auf die Localisation der sie hervorrufenden Läsion im Rückenmarko gewisse Schlüsse gezogen werden. Bei der Halbseitenläsion des Rückenmarkes z. B. beobachteten wir gewöhnlich neben anderen mehr oder weniger gut ausgesprochenen Symptomen der Brown-Séquard'schen Lähmung in der Regel eine complete gekreuzte Hemianalgesie und Hemithermoanästhesie, welche bis za den Zehen herunterreicht. Ueber die Abhängigkeit der oberen Grenze dieser gekreuzten Hemithermoanalgesie von der Höhe der Rückenmarksläsion finden wir in der Litteratur folgende Angaben: in einem Fall von $\mathrm{Lähr}$ stand die obere Grenze der gekreuzten Hemianalgesie und Hemithermoanästhesie um 6 Wirbel tiefer als der Sitz der Hemiläsion des Rückenmarkes; in dem Fall von Reinhardt ungefähr um 6-7 Wirbel; in dem Fall von v. Reusz ungefähr um 3 Wirbel und in dem von Crocq beschriebenen Syndrom von Brown-Séquard'scher Lähmung um 7 Wirbel tiefer als die Rückenmarksläsion. In dem von Wallenberg beobachteten Fall von Ictus apoplecticus in der Gegend der Medulla oblongata befand sich die obere Grenze der gekreuzten Analgesie ungefähr um 6 Wirbel tiefer als der Sitz der Läsion und auch in dem von Mai beschriebenen Fall von halbseitiger Apoplexie in der Medulla oblongata lag die obere Grenze der gekreuzten Analgesie und der Thermoanästhesie auf Kältereize ungefähr um 4-7 Segmente tiefer als die vermuthliche Läsion. In dem Fall von Gumma intramedullare von Hanot und Meunier stand die obere Grenze der gekreuzten Thermoanalgesie nur um 3 Wirbel tiefer als der Sitz der Läsion. In dem von Pribytk off und Versiloff beobachteten Fall von Hämatomyelia centralis des Rückenmarkes nur um 2-3 Wirbel tiefer als der Sitz der Blutung. In dem von Van Gehuchten beschriebenen Fall von Compression des Rückenmarkes lag die obere Grenze der bilateralen Thermoanalgesie nur um 2-3 Wirbel unterhalb der Compressionsstelle. Ed- 
sall beschrieb einen Fall von totaler Compression des Rückenmarkes, in welchem die obere Grenze der Thermoanalgesie uur um 1 Wirbel tiefer lag als die Compressionsstelle selbst. Dasselbe Verhältniss finden wir wieder in dem von totaler Compression des Rückenmarkes, welchen Marinesco beobachtete. Böttiger kommt in der uns hier interessirenden Frage der Abhängigkeit zwischen der Lage der oberen Grenze der gekreuzten Thermoanalgesie und dem Sitz der Rückenmarksläsion, zu folgenden Schlüssen: wenn man die allmälige Kreuzung der Schmerz- und Temperaturleitungsbahn im Rïekenmarke ins Auge fasst, versteht man, warum bei Verletzung des Seitenstranges, bei weleher eine gekreuzte Anästhesie beobachtet wird, dieselbe erst etwa 8 Segmente unterhalb der Läsionsstelle beginnt, Diese klinische Thatsache, sagt Böttiger, kann grosse Bedeutung haben in operablen Fällen. Petrén, der 175 Beobachtungen von Brown-Séquard'scher Paralyse zusammengestellt hat, hebt ebenfalls hervor, dass in einer grossen Anzahl dieser Fälle die obere Grenze der gekreuzten Thermoanalgesie sich in der Regel in einer bestimmten Entfernung von dem Sitz der Rückenmarksläsion befand.

Wenn wir uns auf Grund dieser ganz kurz und nur oberflächlich gesammelten Litteraturangaben eine allgemeine Zusammenfassung zu machen erlauben wollten, müssten wir sagen: die sogenannte syringomyelitische Dissociation der Sensibilität kann cerebralen, peripherischen und spinalen Ursprungs sein; die spinale Thermoanalgesie hat eine radiculäre Topographie; ihre Ausbreitung, resp. die Lage ihrer oberen Grenze hängt von der Höhe der Rückenmarksläsion ab und zwar in der Weise, dass die bei der Compression des Rückenmarkes beobachtete Thermoanalgesie in der Regel gleich unmittelbar unterhalb der Läsionsstelle beginnt, die bei Gummaten des Rückenmarkes oder bei centraler Hämatomyelie beobachtete etwa um 3 Wirbel und die bei einer Halbseitenläsion des Rückenmarkes beobachtete in der Regel um 6-7 Wirbel tiefer beginnt als die Läsionsstelle des Rückenmarkes.

Obwohl die Thermoanalgesie ein kein so seltenes Symptom in der Pathologie der Rückenmarkskrankheiten ist, ist heute die Topographie der die Temperatur- und Schmerzeindrücke leitenden Bahnen im Rückenmarke noch nicht sichergestellt, ja sogar die Existenz solcher Bahnen wird bezweifelt:

I. Manche Autoren fassen die Temperatur- und Schmerzempfindung nur als eine Theilerscheinung der allgemeinen taktilen Sensibilität auf und nehmen nicht an, dass zur Leitung der Temperatur- und Schmerzeindrücke eine besondere Bahn existiren müsse; 
1I. Manche Autoren sind der Ansicht, dass die Temperatur- und Schmerzeindrücke in der grauen Substanz hirnwärts geleitet werden; III. Einige Autoren nehmen an, dass neben der sensiblen Hauptbahn, die in den Hintersträngen liegt, noch eine collaterale Nebenabzweigung dieser Bahn existire, die im gekreuzten Seitenstrang hinaufsteigt und sagen, dass bei. Zerstörung der Hinterstränge nur eine einfache taktile Sensibilität, dagegen bei Zerstörung dieser collateralen Nebenabzweigung im Seitenstrang Thermoanalgesie beobachtet wird;

IV. Die meisten Autoren nehmen jedoch an, dass im Rückenmarke besondere Bahnen existiren, die die Leitung der Temperatur- und Schmerzeindrücke besorgen sollem;

V. Schliesslich giebt es noch Autoren, die besondere Bahnen zur Leitung der Temperaturempfindungen, und besoudere Bahnen zur Leitung der Schmerzempfindungeu annehmen oder sogar an die Existenz einzelner Bahnen für Wärme-, einzelner für Kälte- und einzelner für Schmerzempfindungen glauben.

Ad 1. Dejerine und Thomas sind der Ansicht, dass man einzig und allein in der anatomischen Disposition den Schlüssel zur Erklärung der sogenannten syringomyelitischen Dissociation der Sensibilität nicht wird finden können. Nach ihnen kormmen hier sehr wahrscheinlich nach andere Eigenschaften des Nervensystems in Frage, die sich aber durch unsere beutigen Untersuchungsmethoden nicht feststellen lassen. Nach Dejerine und Thomas ist es heute auch noch unmöglich, irgend eine auf solider Basis ruhende Theorie zur Erklärung des Syndroms von Brown-Séquard aufzustellen. Zur Entstehung der Brown-Séquard'schen Lähmung ist nach Dejerine und Thomas mbedingt nothwendig, dass die graue Substanz auf der einen Seite des Rückenmarkes durchschnitten werde. Mann ist zu der Ueberzeugung gekommen, dass im Rückenmarke eine genaue Trennung der Leitungsbahnen für Tastempfindung einerseits und der Leitungsbahnen für Schmerz- und Temperaturempfindung andererseits undenkbar sei. Wenn man diese Trennung annimmt, kann man garnicht verstehen, warum bei den verschiedenen Rückenmarkskrankheiten immer nur die "syringomyelitische" Dissociation, dagegen nie einen Verlust der Tastempfindung bei gut erhaltener Schmerz- und Temperaturempfindung beobachtet wird. Nach Mann herrscht zwischen den verschiedenen Sensibilitätsqualitäten nur eil quantitativer Unterschied. Stärkere mechanische und thermische Reize rufen specifische Empfindungen des Druckes, des Schmerzes, der Temperatur hervor, schwächere Reize derselben Kategorie rufen nur einfache Tastempfindungen hervor. Deshalb kann die Tastempfindung so zu sagen als die niedrigste Stufe der specifischen Empfindungen auf- 
gefasst werden. Daraus würde sich ergeben, dass die zur Leitung der specifischen Empfindungen bestimmten Bahnen auch die Tastempfindungen leiten können. Mann schliesst sich somit der hente ziemlich verbreiteten Ansicht an, nach welcher das Rückenmark nicht ein einfaches Leitungsorgan für die Schmerzempfindungen darstellt, sondern vielmehr, dass die Schmerzempfindungen im Rückenmark selbst entstehen, in Folge der "Summation der Reize" in den Strangzellen. Sohwohl die Schmerzempfindungen wie die Tastempfindungen haben einen und denselben Weg, nur die Schmerzeindrücke summiren sich in den Strangzellen, dagegen die Tastempfindungen gehen durch die Strangzellen direct durch. Dasselbe nimmt Mann anch für andere Sensibilitätsquantitäten an: überhaupt ganz schwache Temperaturreize oder schwache mechanische Reize, rufen nur Tastempfindungen hervor, stärkere Reize summiren sich im Rïckenmarke, wodurch specifische Empfindungen entstehen sollen. Mann ist sogar geneigt anzunehmen, dass überhaupt alle centripetale Bahnen, ganz unabhängig von ihrer sonstigen Bestimnung, auch Tastempfindungen vermitteln können. Entsprechend dieser Annahme wäre die Thatsache, dass auch bei sehr ausgedehnter Unterbrechung des Leitungsvermögens des Rückenmarkes gewöhnlich die Tastempfindung ungestört bestehen bleibt, wenn nur ein geringer Theil der centripetalen Bahnen noch erhalten ist, sehr leicht zu erklären ist. ${ }^{1)}$ Sie lässt sich aber auch dann leicht erklären, wenn wir mit Edinger, Jolly u. A. annehmen, dass die Leitung der Tastempfindung doppelt angelegt ist, ungekreuzt und gekrenzt. Für Marinesco ist das Phänomen der syringomyelitischen Dissociation der Sensibilität nur ein Ausdruck einer Modification in der Leitung der directen sensiblen Neurone. Die einzig wahre und uns eigene Natur der sensiblen Empfindungen, sagt Marinesco, ist die taktile Sensibilität, während die anderen Sensationen, wie Schmerz- und Temperaturempfindung, nur durch gewisse Aenderungen in der Leitung der directen Neurone bedingte, modificirte oder transformirte Tasteindrücke sind. Und die Frage ob die, z. B. bei der Compression des Rückenmarkes beobachtete, syringomyelitische Dissociation der Sensibilität durch eine Läsion der grauen Substanz bedingt sei oder ob sie dadurch entstehe, dass die sensiblen Nervenbahnen resp. Nervenfasern durch die Compression ihre Eigenschaft, die Temperatur- und Schmerzeindrücke (die nur differencirte oder gesteigerte Stufen der taktilen Sensibilität darstellen) zu leiten, einbüssen, diese Frage ist bis heute immer noch eine offene. Van Gehuchten ist mit der Ansicht von Marinesco, dass die Temperatur- und Schmerzempfindungen

1) Citirt nach Sklodowski. 
nichts anderes darstellen sollen als nur gewisse differencirte Unterstufen der taktilen Sensibilität, nicht einverstanden; er glaubt vielmehr, dass die verschiedenen Sensibilitätsqualitäten von ganz verschiedenen Nervenbahnen geleitet werden und dass das Gowers'sche Bündel eben die zur Leitung der Temperatur- und Schmerzeindrücke bestimmten Bahnen enthalte.

Ad II. Schiff nahm an, dass die Temperatur- und Schmerzempfindungen in der grauen Substanz geleitet werden. Herzen stellte auf Grund der Beobachtung eines Falles von Pachymeningitis bypertrophica die Hypothese auf, dass die Tast- und Kälteempfindungen in den Hintersträngen, die Schmerz- and Wärmeempfindungen dagegen in der grauen Substanz hirnwärts geleitet werden. Nach Dejerine und Thomas ist zur Entstehung des Brown-Séquard'schen Syndroms unbedingt nothwendig, dass die graue Substanz auf einer Seite des Rückenmarkes durchschnitten sei. Für Vines ist die Ursache der syringomyelitischen Dissociation der Sensibilität, die bei Compression des Rückenmarkes beobachtet wird, in einer Läsion der grauen Substanz zu suchen. $V$ an Gehuchten hebt jedoch mit Recht hervor, dass wenn man eine complete syringomyelitische Dissociation der Sensibilität (vom Fuss hinaufsteigende) auf diese Weise erklären wollte, müsste man annehmen, dass die graue Substanz unterhalb der Compressionsstelle in der ganzen Ausdehnung des Rückenmarkes lädirt sei. Eine solche Läsion würde aber die Aufhebung jeglicher Reflexbewegungen in dem unter der Compressionsstelle gelegenen Körpertheile zur Folge haben, was jedoch bei den von Van Gehuchten und Edsall beobachteten Patienten nicht der Fall war. Oder aber, sagt Van Gebuchten, da das Hauptleitungsorgan doch die Nervenfaser sei, müsste man in der grauen Substanz des Rückenmarkes die Existenz langer Babnen nachweisen, was bis jetzt ausser Ciaglinki Niemandem gelungen ist. Auf Grund von experimentellen Untersuchungen von Schiff und anf Grund ihrer pathologischen Beobachtungen kamen v. Leyden und Goldscheider zu der Ueberzeugung, dass die Leitung der Temperatur- und Schmerzeindrücke hauptsächlich von der grauen Substanz besorgt werde; die graue Substanz sei zwar nicht ein eigentliches Organ zur Leitung der Erregungen, aber zum Zustandelzommen einer Schmerzempfindung sei die graue Substanz doch unerlässlich, denn damit ein Reiz, der die Haut trifft, als schmerzlich empfunden wird, muss derselbe die hintere graue Substanz des Rückenmarkes passiren. Diese Transformation und Transmission der Schmerzeindrücke ist nur eine specielle Abart der allgemeinen Eigenschaft der grauen Substanz, die Reize zu summiren. Es sei sehr wahrscheinlich, dass die thermische Sensibilität, vor allem aber 
die Wärmeempfindung auch ein Phänomen der Summation der Reize sei, welche ebenfalls in der grauen Substanz stattfinde.

Ad III. Die Leitung der Tasteindrücke geschieht nach Goldscheider in den Hintersträngen und wie die Forschungen von Edinger, Jolly u. A. vermuthen lassen, auch in den Vorderseitensträngen. Zur Erklärung der Leitung der Temperatur- und Schmerzempfindung stellten v. Leyden und Goldscheider folgende Hypothese auf: Jede Faser der Hinterstränge entsende nach von Leyden und Goldscheider Collateralen zur grauen Substanz ab. Und num, wenn die Erregungen nicht zu stark sind, werden sie allein von den Fasern der Hinterstränge weiter befördert, stärkere jedoch gehen auf diese Collateralen über. Eine ähnliche Theorie stellte auch schon von Reusz auf. Wenn dies aber richtig wäre, müssten wir ja bei einer Läsion der Hinterstränge neben der Anästhesie auch noch Thermoanalgesie beobachten - was nicht der Fall ist.

Ad IV. Schon früher neigten solche Forscher wie Funke, Brücke und Brown-Séquard zur Annahme der Existenz im Rückenmarke getrennter Bahnen zur Leitung des Schmerzgefühls und der Tastempfindung. Sie stïtzten sich dabei hauptsächlich auf das Vorkommen der Dissociation der Sensibilität bei Tabes dorsalis und auf Brown-Séquard'sche Beobachtungen der Dissociation der Sensibilität nach Seitenverletzung des Rückenmarkes aus den 70 er Jahren. Erst aber seit den 80 er Jahren und nämlich seit der Entdeckung von Kahler und Schultze der Dissociation der Sensibilität bei Syringomyelie, fing man an das Symptom der syringomyelitischen Dissociation der Sensibilität näher zu studiren, dasselbe anatomisch zu begründen und sich näher mit der Hypothese der Existenz getrennter Bahnen zur Leitung verschiedener Sensibilitätsqualitäten näher zu befassen (citirt nach Sklodowski). Heute nehmen die meisten Autoren an, dass zur Leitung der Temperatur- und Schmerzeindrücke im Rückenmarke besondere Nervenbahnen vorbanden sein müssen. Und wenn man sich daran erinnert, dass es Verletzungen des Rüekenmarkes giebt, bei welchen als einzige und isolirte krankhafte Erscheinung nur der Ausfall der Temperatur- und Schmerzempfindung constatirt wurde, so ist man wirklich gezwungen an die Existenz einer solchen speciellen Nervenbahn zu glauben, um so mehr als in einigen solchen Fällen eine Läsion der Hinterstränge, in welchen die sensiblen Bahnen verlaufen, ausgeschlossen werden konnte. Erwähnen will ich hier auch, dass z. B. Dejerine und Thomas die Erklärung von Raymond und Brissaud, dass das Symptom der Thermoanalgesie bei erhaltener tactiler Sensibilität von dem Intactsein der Hinterstränge abhängen soll, nicht ohne Weiteres acceptiren, da, wie sie sagen, dieses 
Zum Studium der Dissociation der Temperatur- u. Schmerzempfindung. 959

Symptorn auch bei Läsion beider Hinterstränge in einem Fall von Charcot und Gombauld vorhanden sein sollte. Die Annahme der oben erwähnten doppelten Anlage für die Leitung der Tasteindrücke: in den Hinter- und den Vorderseitensträngen, liesse heute den Fall von Charcot und Gombauld leicht erklären. Kocher ist der Ansicht, dass die Schmerzempfindung in den Seitensträngen geleitet wird. Edinger, Schlesinger, Lähr, von Reusz, Henneberg u. A. sind der Ansicht, dass die zur Leitung der Temperatur- und Schmerzempfindungen dienenden Bahnen, nachdem sie das Hinterhorn erreicht haben, dasselbe bald wieder verlassen und nachdem sie die Medianebene passirt haben, im contralateralen Seitenstrange weiter ziehen. Auch aus den experimentellen Dntersuchungen von Bechterew und Holzinger geht hervor, dass wenigstens beim Hunde die Leitungsbahnen für die Schmerzempfindungen in den gekrenzten Seitensträngen liegen müssen.

Neulich nahm wieder de Goy on bei Hunden und Katzen halbseitige Durchschneidung des Rückenmarkes, einfacbe und doppelte vor, und indem er seine Resultate mit den Ergebnissen der klinischen Beobachtung verglich, kam er zu folgenden Schlüssen: im Rückenmark der Thiere und des Menschen muss man verschiedene Bahnen für die Leitung der Temperatur-, der Schmerzempfindung; sowie der tactilen Sensibilität annehmen. Beim Hunde und beim Menschen erscheinen die Bahnen für die Schmerz- und Temperaturempfindung total gekreuzt durch die ganze Höhe des Rückenmarkes. Die Kreuzung liegt in der grauen Substanz und die gekreuzten Bahnen gelangen in den Seitenstrang. Die Tastempfindung und der Muskelsinn werden durch die Hinterstränge geleitet; ihre Bahnen verlaufen im Rückenmark ungekreuzt. Auf Grund der Beobachtung eines Falles von halbseitiger Verletzung des unteren Halsmarkes, der zur Section kam, ist Mann zu der Ueberzeugung gekommen, dass man in den vorderen Seitenstrangresten die anatomische Bahn für die gekreuzten sensiblen Empfindungen suchen muss. Nach Rossolimo führt der Hirnstamm, analog dem Rückenmark, specielle Leitungsbahnen für Wärme- und Schmerzempfindung, welche böchst wahrscheinlich in den lateralen Regionen seiner dorsalen Abschnitte gelegen sind, und welche eine Fortsetzung einiger Fasern des Grundbündels des Vorderstranges des Rückenmarkes bilden, die aber nicht mit dem Gowers schen Bündel coincidiren. Bálint beobachtete einen 33jährigen Patienten mit syphilitischer Affection des Hirnstammes. Neben linksseitiger Hemiplegie mit Lähmung des linken Facialis und rechten Oculomotorius bestand linksseitige Thermoanästhesie und Analgesie. Die motorischen Lähmungen schwanden nach mehreren Wochen vollständig; während 
die Sensibilitätsstörungen stabil blieben. Als Sitz der Läsion supponirt Bálint einen Herd in der Nähe des Oculomotoriuskernes rechts, welcher den rechten Pedunculus berührt oder dräckt. Mangels beweisender Sectionsbefunde lässt sich der Sitz jener Läsion, welche die Sensibilitätsstörung verursacht, nicht bestimmen. Sicher zu sein scheint, sagt B cliut, dass Temperatursinu und Schmerzgefühl gesonderte Bahnen bis zur Himrinde besitzen, und dass diese in dorsalen Theile des Hirnstammes, wahrscheinlich in der Substantia reticularis zu suchen sind.

v. Reusz macht auch darauf aufmerksam, dass bei der Autopsie von Kranken, die zeitlebens eine Thermoanalgesie aufwiesen, sich gewöhnlich ein circumscriptes degenerirtes Feld in der weissen Substanz, seitlich vom Vorderhorm nachweisen lässt. van Gehuchten nimmt an, dass die verschiedenen Sensibilitätsqualitäten von verschiedenen Nervenbahuen geleitet werden und dass das Gowers'sche Bündel eben die zur Leitung der Temperatur and Schmerzeindrücke bestimmten Fasem enthält und dass die Uranche der syringomyelitischen Dissociation der Sensibilität in einer anatomischen oder functionellen Unterbrechung der Fasern des Gowers'schen Bündels zu suchen sei. Brissaud, Llyod, Grasset, Petrén, Kohnstamm und $\mathrm{Mai}$ sind auch der Ansicht, dass die Temperatur- und Schmerzempfindung ${ }^{1}$ ) in dem contralateralen Gowers'schen Bündel hirnwärts geleitet werden. van Gehuchten begründet seine Auffassung nicht nur durch klinische Eriahrung, sondern auch durch Resultate der experimentellen pathologischen Anatomie. Aufsteigende Degeneration nach transversaler experimenteller Section des Rückenmarkes, sagt er, finden wir nur: in den Goll'schen Strängen, in der Kleinhirnseitenstrangbahn and in dem Gowers'schen Bündel. Also nur unter diesen degenerirenden Fasern können wir die zur Leitung der Temperatur- und Scbmerzeindrücke bestimmten Bahnen suchen, wenn wir ïberhaupt annehmen, dass sie gesonderte Bahuen bilden und von denjenigen Bahnen', welche die Tasteindrücke und die Muskelsinnempfindungen leiten, getrennt verlaufen. Die Goll'schen Stränge können wir, sagt van Gehuchten, ausschliessen, weil sie aus ungekreuzten Fasern bestehen und weil sie nur Tasteindrücke und vielleicht auch noch Muskelsinnempfindungen leiten, desgleichen können auch die Kleinhjrnseitenstrangbahnen ausgeschlossen werden, da sie nur Muskelempfindungen leiten und auch nur aus ungekreuzten Fasern bestebeu,

1) Eigentiich sind es nicht die Empfindungen, sondern nur die Reize, die im Rückenmarke fortgeleitet werden, denn die Empfindung ist der Ausdruck eines psychischen Processes, welcher im Gebirn, beim Anlangen des entsprechenden Reizes, erregt wird. 
Zum Studium der Dissociation der Temperatur- u. Schmerzempfindung. 961

die Bahnen zur Leitung der Temperatur- und Schmerzempfindungen dagegen gekreuzte Bahnen sind. Es bleiben somit nur die Fasern des Gowers'seben Bündels, welche zum grössten Theil ans gekreuzten Fasern bestehen. Sie dienen auch van Gehuchten ausschliesslich zur Leitung der Temperatur- und Schmerzeindrücke. Auf Grund eigener Beobachtung von drei Fällen von acuter Myelitis sypbilitica und der Zusammenstellung anderer aus der Literatur, kam Petrén, ähulich wie Mann, zur Annabme, dass die gekreuzte Sensibilitätsstörung bei einseitiger Rückenmarksverletzung in der Mehrzahl der Fälle die Form einer dissociirten Anästhesie anzunehmen pfiegt: Aufhebung des Schmerzund des Temperatursinnes bei normalem Drucksinn.

In gewissen Fällen kommt jedoch auch unzweifelhaft eine totale, gekreuzte Hautanästhesie vor. Diese gekreuzte Anästhesie umfasst aber alle Hautsinne nur in denjenigen Fällen, in welchen die motorische Lähmung unmittelbar nach dem Unglüeksfall eine doppelseitige ist; der Drucksinn bleibt dagegen unbeeinträchtigt in denjenigen Fällen, in denen die Lähmung schon von Anfang an nur auf eine Seite beschränkt ist. Dies beweist nach Petrén ${ }^{1}$ ), dass die Leitungsbabn für den Drucksinn im Rückenmark näher der Mittelebene liegen muss, als die Bahnen für den Schmerzsinn und für die Temperatursinne und dass also die Bahnen für den Drucksinn nicht mit denen für den Schmerzsinn und die Temperatursinne zusammenfallen. Aus seinen Fällen geht auch unter Anderem hervor, dass die Zerstörung eines Hinterhorns im Halsmark Verlust des Schmerzsinnes und der Temperatursinne im Arme derselben Seite mit sich bringt, dass also die Bahnen dieser Sinne nach ihrem Eintreten in das Rückenmark im hinteren Horne derselben Seite verlaufen. In ihrem weiteren Verlaufe nach oben zu müssen sie, wie sich aus anderen Fällen ergeben hat, in die weisse Substanz der gekreuzten Seite übergehen. Da nun aber die Vorder- und Hinterstränge unmittelbar bis zur Mittelebene reichen, dagegen, wie schon erwähnt, die Bahnen des Schmerzsinnes und der Temperatursinne weiter von der Mittelebene entfernt verlaufen müssen als die des Drucksinnes, so ist es höchstwahrscheinlich, dass sie in den Seitensträngen zu suchen sind. Nach Petrén ist heute als sicher festgestellt zu betrachten, dass die Leitungsbahnen für den Schmerzsinu und die Temperatursinne der Gliedmaassen in den gekreuzten Seitensträngen verlaufen und als sehr wahrscheinlich, dass diese Bahnen in den Seitensträngen nicht bis an die

1) Citirt fast wörtlich nach dem ausgezeichneten Referat im Neurol. Centralbl. (1902, S. 538) von Walter Berger. 
graue Substanz reichen, sondern in der lateralen Hälfte der Seitenstränge liegen.

Was die Bahn für den Drucksinn betrifft, lässt sich die Annahme, dass sie in den Hintersträngen zu suchen sei, weder mit unseren anatomischen, noch mit unseren pathologischen Erfahrungen in Uebereinstimmung bringen; dieselbe kann, sagt Petrén, auch nicht nur in einem Bezirke des Rückenmarksquerschnittes verlaufen, sondern muss wenigstens in $z$ weien gesucht werden, $d . h$. dass diese Bahn doppelt angelegt sein muss. In der That können wir alle die verschiedenen daraufbezüglichen Beobachtungen leicht erklären, wenn wir annehmen, dass der Drucksinn zum Theil in den Hintersträngen und zum Theil in (ungefähr) denselben Bahnen verläuft, wie der Schmerzsinn und die Temperatursinne, nämlich dureh das hintere Horn derselben Seite, durch die Mittelebene, durch eine der Commissuren und weiter oben durch den Seitenstrang der anderen Seite. Was den Verlauf des Drucksinnes in den Hintersträngen betrifft, so ist es von allen Gesichtspunkten aus am wahrscheinlichsten, dass er in die anfsteigende exogene Bahn zu verlegen ist, die anatomisch wohlbekannte, mächtige Bahn, die ungekreuzt ist. In Bezug auf die Frage, ob wir die Leitung der Hautsinne auf anatomisch bekannte Bahnen zurückführen können, kommt Petrén za dem Schlusse, dass unsere anatomischen Kenutnisse von den Gowers'schen Strängen in keiner Weise die Annahme unwahrscheinlich machen, dass die gekreuzten Bahnen der Hautsinne, die in den Seitensträngen liegen, eben in die Gowers'scben Bündeln zu verlegen seien, vielmehr gewinnt diese Annahme durch verschiedene Beobachtungen einen hohen Grad von Wahrscheinlichkeit. Seine eigenen Untersuchungen fasst Petrén in dem. Schlusssatz zusammen, dass sämmtliche vier Hautsinne durch den gekreuzten Seitenstrang geleitet werden, und zwar mit grösster Wahrscheinlichkeit in seiner lateralen Hälfte; wahrscheinlich bildet ihre Bahn ein Theil der Gowers'schen Bahn oder die ganze; ausserdem verfügt der Drucksinn noch über eine andere Bahn in dem gleichseitigen Hinterstrange, die mit aller Wahrscheinlichkeit von der directen Verlängerung der aufsteigenden Nervenfasern der hinteren Wurzeln gebildet wird. Ein Jahr später kam Petrén auf Grund einer Zusammenstellung von 175 Beobachtungen des Brown-Séquard'schen Syndroms nach Halbseitenläsion des Rückenmarkes zu folgenden Schlüssen:

1. Diejenigen Bahnen, welche die Leitung der Schmerz- und Temperatureindrücke besorgen, gelangen zuerst in das Hinterhorn;

2. Diese Bahnen (verlassen bald das Hinterhorn und) erleiden in der Medianebene vollständige Kreuzung mit den von der anderen Seite 
Zum Studium der Dissociation der Temperatur- u. Schmerzempfindung. 963

kommenden, gleichnamigen Bahnen. Diese Kreuzung vollzieht sich auf einer Höhe von 3-5 Medullarsegmenten;

3. Diese Bahnen erreichen schliesslich die laterale Partie der Vorderseitenstränge auf einer Höbe yon $5-7$ Medullarsegmenten; unterwegs passiren sie durch die mediane Partie der Vorderseitenstränge;

4. Dies zwingt zur Aunabme einer allmäligen Verschiebung (während des aufsteigenden Verlaufes) dieser Bahnen in dem Vorderseitenstrange von der medialen Abtheilung bis zu der lateralen Peripherie desselben.

Allen diesen Bedingungen des Verlaufes dieser die Temperaturund Schmerzeindrücke leitenden Bahnen, entsprechen nach Petré ı vollständig die Fasern des Tractus antero-lateralis ascendens oder des Gowers'schen Bündels:

1. Die Hauptmasse der Fasern des Gowers'schen Bündels kommt auch aus dem Hinterhorn;

2. die allmälige Kreuzung dieser Fasern in der Medianebene geschieht ebenfalls auf einer Höhe von drei Medullarsegmenten;

3. diese Fasern gehen ebenfalls in die laterale Parthie des Vorderstranges über und

4. die allmälige Verschiebung dieser Fasern im Vorderseitenstrange kommt ebenfalls auf einer Höhe von fünf Medullarsegmenten zu Stande.

Nach Kohustamm erleiden die schmerz- und temperaturleitenden Fasern eine Kreuzung mit den von der anderen Seite kommenden auch auf einer Höhe von ungefähr drei Segmenten bis sie zur medianen Partie des Vorderseitenstranges der anderen Seite angelangt sind. Die darauffolgende allmälige Verschiebung dieser Fasern im Vorderseitenstrang selbst bis zum Gowers'schen Bündel kommt auch erst auf einer Höhe von 3- 5 Hedullarsegmenten zu Stande.

In Bezug auf den Verlauf dieser vermuthlichen Nervenbahnen durch die graue Substanz des Rückenmarkes finden wir in der Literatur folgende Angaben: der grösste Theil der lateralen Abtheilung der Fasern der hinteren Wurzeln zersplittert sich nach Edinger, wach einem mehr oder weniger langen Verlauf in dèr weissen Substanz, um die Zellen der Hinterhörner herum. Diese Zellen bilden dann den Ursprung eines zweiten Neurons, dessen Axencylinder nach der Kreuzung in der Medianebene schliesslich in dem contralateralen Vorderseitenstrang weiter hirnwärts zieht. Diese Bahn, sagt Edinger, enthält ohne jeden Zweifel auch diejenigen Fasern, welche zur Leitung der Temperatur- und Schmerzeindrücke dienen. Da aber nach Schlesinger eine Zerstörung der Hinterhörner (mit Ausnahme der Clarke'schen Säulen) keine wichtigen aufsteigenden Degenerationen nach sich zieht, kann dieses zweite Neuron nicht in den Zellen der Hinterhörner und auch nicht vor der 
Kreuzung beginnen. Schlesinger meint, dass dieses zweite Neuron in den Zellen des centralateralen Vorderhorns seinen Ursprung nimmt. Dieselbe Ansicht vertritt auch Brissaud. Grasset dagegen theilt die Ansicht von Edinger. Schlesinger nimmt im Weiteren an, dass die Kreuzung in der vorderen Commissur stattfinde.

Diese hier kurz skizzirte Ansicht von Van Gehuchten, Brissaud, Llyod, Grasset, Petrén, Kohnstamm, Mai u. A. über den Verlauf der die Temperatur- und Schmerzeindrücke leitenden Bahnen wird hauptsächlich von Dejerine und Thomas, Herzen und Hoche angegriffen. Dejerine und Thomas können die Ansicht, dass die Temperatur- und Schmerzeindrücke leitenden Bahnen im gegenseitigen Gowers'schen Bündel verlaufen, desshalb nicht acceptiren, weil die Degeneration des Gowers'schen Bündels nach der Ansicht dieser Forscher keine Störung der Sensibilität hervorzurufen braucht. Herzen stützt sich sowohl auf eine klinische Beobachtung wie auch auf die Resultate seiner Thierexperimente: In einem Fall von Pachymeningitis hypertrophica mit Zerstörung der Hinterstränge und der Kleinhirnseitenstrangbahn constatirte Herzen vollständigen Verlust der taktilen Sensibilität und der Sensibilität auf Kältereize mit Erhaltensein der Schmerz- und Wärmeempfindung. Auf Grund dieses Falles stellte Herzen die Hypothese auf, dass die Tast- und Kälteempfindung in den Hintersträngen, und die Schmerzund Wärmeempfindungen in der grauen Substanz birnwärts geleitet werden. Diese Hypothese wird jedoch von Goldscheider und Mai bekämpft. Mai sagt nämlich, dass man den Verlust der Kälteempfindung in dem Herzen'schen Fall auch dureh eine Compression des Gowers'schen Bündels erklären könnte; er erinnert daran, dass seiner Zeit Herzen und Goldscheider fast gleichzeitig die Beobachtung gemacht haben, dass bei Steigerung des auf einen peripherischen Nerven ausgeübten Druckes zuerst die Sensibilität auf Kältereize und später erst die Sensibilität auf Wärmereize verschwinde ${ }^{1}$, was vielleicht be-

1) Zu ähnlichen Resultaten, wie Herzen und Goldscheider, kam ganz unabhängig von ihnen auch Biornacki, der seine Untersuchungen am Nervus ulnaris angestellt hat. Er überzeugte sich, dass, wenn man auf peripherische Nerven einen mechanischen Druck ansübt, zuerst sich neben einer Anästhesie für Kälte eine Hyperästhesie der Wärme- und Schmerzempfindung einstellt und erst später kommt es zu einer Abstumpfung der Schmerzempfindung und des Drucksinns. Der Tastsinn bleibt meistens ungestört erhalten, aber dies nur bis zu einem gewissen Grade. Obwohl die Patienten von Biernacki auch die leichtesten Berührungen wahrnahmen, gaben sie doch an, dass die Empfindungen etwas stumpf waren, nämlich sie hatten die Empfindung, als ob man sie durch dazwischen gelegtes Leintuch oder Papier berührte, was Biernacki 
weisen würde, dass die zur Leitung der Kälteeindrücke dienenden Fasern eine geringere Resistenzfähigkeit besitzen, als diejenigen, die die Wärmereize leiten. Goldscheider erklärte den Verlust der Kälteempfindung in dem Fall von Herzen auch auf diese Weise, indem er annahm, dass der mechanische Druck bei Pachymeningitis hypertrophica analogen Einfluss auf die Nervenbahnen des Rückenmarkes ausübe wie die Compression auf einen peripherischen Nerven. - Beim Hunde hat Herzen nach einer completen Halbseitendurchschneidung des Rückenmarkes folgendes constatirt: gleichseitigen Schwund der taktilen Sensibilität, des Huskelsinnes und der Kälteempfindung bei vollkommen erhaltener Schmerzempfindung auf beiden Seiten. Daraus zieht Herzen den Schluss:

1. dass jede Rückenmarkshälfte eine genügende Anzahl von Communicationsmitteln enthält zur Leitung der Schmerzeindrücke, die von beiden Körperhälften kommen,

2. dass die Annahme einer totalen Kreuzung der die Schmerzeindrücke Ieitenden Bahnen unbaltbar sei und

3. dass die Leitungsbahnen der taktilen Sensibilität, des Muskel-

auf eine Abstumpfung des Drucksinnes zurückführt. Nach Biernacki besitzt die sensible Drucklähmung gewisse Eigensehaften, die sie von der syringomyelitischen Dissociation der Sensibilität wesentlich unterscheiden. Bei der typisohen syringomyelitisohen Dissociation ist der Tastsinn vollkommen erhalten, dagegen bei der Drucklähmung der Sensibilität ist der Drucksinn abgeschwächt. Ein zweites wichtiges Merkmal einer Drucklähmung der Sensibilität ist nach Biernacki das Erhaltensein der Schmerzempfindlichkeit auf den faradischen Strom bei gleichzeitiger Unempfindlichkeit auf andere Schmerzreize. Diese beiden Merkmale sollen nach Biernacki die bei der Compression eines peripherischen Nerven beobachtete Dissociation der Sensibilität von der syringomyelitischen Dissociation onterscheiden. Sklodowski macht jedoch darauf aufmerksam, dass auch bei der Syringomyelie der Drucksinn nicht immer intact gefunden wird und citirt nach Schlesinger einen Fall von Roth, wo der Drucksinn deutlich abgeschwächt war, trotz des Erhaltenseins des Tastsinns. Zu dem zweiten ron Biernacki aufgestellten Unterscheidungsmerkmal, bemerkt Sklodowski, dass, da Mana in seinen 6 Fällen der BrownSéquard'schen Lähmung, die doch nicht zur Syringomyelie gehören, vollständige Anästhesie auf den faradischen Strom constatirt hat, man die in diesen Fällen beobachtete Dissociation der Sensibilität zu der Drucklähmung rechnen müsste. Warum dies so sein sollte, verstehe ich nicht. Mir scheint es nur, dass, da in diesen Fällen von Mann die Empfindung auf den faradischen Strom aufgehoben war, wir gerade mit Biernacki sagen können, dass die in diesen Fällen beobachtete Dissociation der Sensibilität eben gerade nicht mit der Drucklähmung der Sensibilität verwechselt werden kann. 
sinnes und der Kälteempfindung nur in der gleichnamigen Hälfte des Rückenmarkes enthalten sind.

Auf Grund einer Zusammenfassung der Resultate dieses Versuches mit den Resultaten der Thierexperimente von Schiff und andererseits mit den Resultaten einer beiderseitigen Halbseitensection (auf versehiedenen Höhen) des Rückenmarkes (wobei von Herzen beiderseitige Tastund Kälteanästhesie mit Erhaltensein der Schmerzempfindung auf beiden Seiten beobachtet wurde), gelangt Herzen in Bezug auf die Leitung der Sensibilität zu folgender Ueberzeugung:

1. Die taktile Sensibilitatt wird von einem oder dem anderen Strange der weissen Substanz geleitet. (Diese Bahn besteht aus langen Fasern).

2. Da bei einer Hemisectio unilateralis duplex alle weissen Stränge durchgeschnitten werden, ist es unmöglich anzunehmen, dass einer derselben zur Leitung der Schmerzeindrücke, welche erbalten sind, dienen könute.

3. Da bei der Hemisectio unilateralis duplex die beiden Hälften des Rückenmarkes nur durch die graue Substanz untereinander verbunden sind, muss man annehmen, dass nur die graue Substanz es sein kann, die die Schmerzeindrücke leitet, da die Schmerzempfindung dabei auf beiden Seiten des Körpers erhalten bleibt. Diese Ansicht schliesst sich, wie wir sehen, vollkommen der alten Ansicht von Schiff an.

Da im Weiteren, wie Herzen sich überzeugt hat, die Section der vorderen Rückenmarkshälfte sowohl wie auch die experimentelle Zerstörung derjenigen weissen Substanz, welche zwischen den beiden grauen Hörnern liegt, d. b. derjenigen Partie des Seitenstranges, die bekanntlich aus der Kleinhirnseitenstrangbahn, aus der Pyramidenseitenstrangbahn und dem Gowers'schen Bündel besteht, weder die taktile noch die Schmerzempfindung aufhebt, können diese Bahnen, führt Herzen im Weiteren aus, keine Rolle spielen bei der Leitung der Sensibilität. Somit sei auch jede Betheiligung des Gowers'schen Bündels bei der Leitung der Sensibilität ein für alle Mal ausgeschlossen. Die Section der Hinterstränge hebt nur die talktile Sensibilität auf. Daraus folgt, sagt Herzen, dass die Leitungsbahnen der taktilen Sensibilität einzig und allein in den weissen Strängen der hinteren Hälfte des Rückenmarkes enthalten seien. Da aber die Section der Hinterstränge ausser der taktilen Sensibilität auch noch die Leitung der Kälteeindrücke aufhebe, muss man annehmen, sagt Herzen, dass die Leitung dieser beiden Sensibilitätsqualitäten in den gleichseitigen Hintersträngen vereinigt ist. In Bezug auf die Leitung der Wärmeempfindung nimmt Herzen als wahrscheinlich an, dass dieselbe in der grauen Substanz stattfinde. Die Versuche von Bechterew und Holzinger, welche manche Autoren zur 
Unterstützung ihrer Hypothese, dass das Gowers'sche die Leitung der Temperatur- und der Schmerzeindrücke besorge, anführen, beweisen nach Herzen vielmehr dies, dass der grösste Theil des Gowers'schen Bündels bei Thieren zerstört sein kaun, ohne eine Analgesie hervorzurufen. Was diese experimentellen Versuche von Herzen anbelangt, möchte ich mir nur die Bemerkung erlauben, dass dies alles für den Hund richtig sein mag; dies beweist jedoch noch nicht, dass dieselben Verhältnisse auch beim Menschen existiren müssen. Dejerine macht ja darauf aufmerksam, dass z. B. die Kreuzung der Leitung dieser Sensibilitätsqualitäten im Rückenmarke bei verschiedenen Thiergattungen von einer partiellen bis zu einer vollständigen variiren kann. Bei dieser Gelegenheit möchte ich noch einmal daran erinnern, dass, im Gegentheil zu Herzen, Bechterew und Holzinger auf Grund ihrer physiologischen Untersuchungen zu dem Schluss gekommen sind, dass die Schmerzempfindungen in den Seitensträngen geleitet werden. Holzinger konnte bei Thieren bloss durch Durchtrennung der Seitenstränge Analgesie des unterhalb gelegenen Körperabschnittes erzielen, ebenso durch Durchschneidung der hinteren Rückenmarkshälfte bis etwas vor die Pyramidenbahn. Und neulich nahm wieder de Gyon bei Hunder und Katzen halbseitige Durchschneidung des Rückenmarkes, einfache und doppelte, vor und indem er seine Resultate mit den Ergebnissen der klinischen Beobachtung verglich, kam er zu folgenden Schlüssen: im Rückenmark der Thiere uud des Menschen muss man verschiedene Bahnen für die Leitung der Temperatur-, der Schmerzempfindung, sowie der taktilen Sensibilität annehmen. Beim Hunde und beim Menschen erscheinen die Bahnen für Schmerz- und Temperaturempfindung total gekreuzt durch die ganze Höhe des Rückenmarkes. Die Kreuzung liegt in der grauen Substanz, und die gekreuzten Bahnen gelangen in den Seitenstrang.

Hoche fand, dass die Fasern des Fasciculus antero-lateralis ascendens Gowersi fast ausschliesslich zum Kleinhirn ziehen. Dies, sagt Mai, kann aber auch nicht als ein Argument gegen die Annahme, dass die Temperatur- und Schmerzeindrücke leitenden Fasern im Fasciculus antero-lateralis ascendens verlaufen, geltend gemacbt werden, weil auf der anderen Seite Thomas, Petrén und Bruce gezeigt haben, dass ein Theil der Faseru des Fasciculus antero-lateralis ascendens im Seitenstrang endige. Bruce hat sie sogar bis zu den Tubercula quadrigemina, Quernel - bis zum Corpus geniculatum internum und sogar bis zum Thalamus, Rossolimo - bis zu den hinteren Vierhügeln, der Substantia nigra und zum Globus pallidus verfolgen können. Nach Bechterew soll sich ein Theil der Fasern des Seitenstranges auf der 
Höhe der Olive der medialen Schleife anschliessen. Dydyuski untersuchte mit der Marchi'schen Methode einen Fall von Myelitis transversa im oberen Dorsalmark, wobei die Degeneration des Gowers'schen Bündels sich bis zum Thalamus opticus verfolgen liess. Wenn man dies alles in Erwägung zieht, muss man, sagt Mai, doch annehmen, dass beim Menschen ein nicht unbeträchtlicher Theil der Fasern des Gowers'schen Bündels bis zu den Vierhügeln, zum Corpus geniculatum internum und zum Thalamus zieht. Dasselbe hat man auch bei Thieren gefunden: z. B. bei Amphibien und Fischen constatirte zuerst Edinger das Vorhandensein eines ganzen Systems von Fasern, welche von den Hinterbörnern bis zum Thalamus hinaufsteigen. Wallenberg, Probst und Kohnstamm, der den Verlauf dieser Fasern beim Kaninchen studirte, unterscheidet im Tractus antero-lateralis ascendens: 1. das eigentliche Gowers'sche Bündel, welches zum Kleinhirn zieht und 2. die Edinger'schen Fasern, d. h. Neurone, welche, von dem contralateralen Hinterhorn stammend, bis zum Thalamus verfolgt werden können.

Bei dieser Gelegenheit möchte ich auf eins anfmerksam machen: Ich will mir durchaus nicht erlauben, die oben erwähnte Angabe meines hochverehrten Lehrers, des Herrn Prof. Dejerine, nach welcher es Fälle giebt mit Degeneration des Gowers'schen Bündels, die keine wahrnehmbare Sensibilitätsstörungen aufweisen, zu kritisiren, aber wenn die Ansichten von Kohnstamm richtig sind, möchte ich doch die Frage aufwerfen, ob vielleicht in dem von Dejerine citirten Fall nicht gerade nur die zum Kleinhirn ziehenden Fasern in Degeneration begriffen waren, die sogenannten Edinger'schen Fasern des Gowers'schen Bündels dagegen intact waren, was den Mangel von Sensibilitätsstörungen auch erklären würde?

Ad V. Manche Forscher nehmen an, dass im Rückenmarke für alle Sensibilitätsqualitäten gauz besondere und verschiedene Nervenbahnen existiren müssen. Van Gehuchten z. B. ist auf Grund der bei Syringomyelie gemachten Erfahrungen zu der Ansicht gekommen, dass nicht alle sensiblen Fasern dieselben physiologischen Functionen erfüllen. Er nimmt zur Leitung verschiedener Sensibilitätsqualitäten die Existens verschiedener Nervenbahnen an, besonderer zur Leitung der Schmerzempfindungen, besonderer zur Leitung der Wärme- und besonderer zur Leitung der Kălteempfindungen. Schlesinger sagt, dass unsere klinischen Erfahrungen darauf hindeuten, dass wenigstens im Rückenmarke eine gesonderte Leitung der Wärmeeindrücke und eine gesonderte Leitung. der Kälteindrücke vorhanden sein muss. $\mathrm{Yla}$ i ist auch zu der Ueberzeugung gelangt, dass die Bahnen des Wärme- und Kältesinnes wohl 
örtlich nahe am Tractus antero-lateral. ascend. liegen; es muss jedoch für diese beiden Sinne eine getrennte centrale Leitung vorhanden sein. Um die Dissociation der Sensibilität in seinem Fall zu erklären, glaubt er jedoch nicht die Existenz dreier anatomisch ganz gesonderter Bahnen annehmen zu müssen. Es liegt viel näher - sagt er - einen gewissen noch unbekannten Unterschied in der Structur oder im Chemismus dieser verschiedenen specifischen Nervenfasern anzunehmen, welcher eine verschiedene Resistenzfähigkeit dieser Fasern gegenüber der schädlichen Noxe erklären würde. Und das Vorhandensein einer subjectiven Sensation der Wärme bei seinem Kranken, bei dem die Kälteempfindung aufgehoben war, erklärt sich Mai auf diese Weise, indem or annimmt, dass dieselbe schädliche Noxe, welche die Leitungsfasern für Kälte paralysirt hatte, zu gleicher Zeit die Leitungsfasern für Wärme erregte. Goldscheider machte ja auch schon früher die Beobachtung, dass bei Compression eines peripherischen Nerven oft zuerst die Kälteempfindung verschwindet, während eine Hyperästhesie auf Wärmereize constatirt wird.

Giebt es in der Literatur Anhaltspunkte, welche die Existenz solcher isolirten Leitungsbahnen für Schmerz-, Wärme- und Kälteempfindungen wahrscbeinlich machen könnten? - ja. Das sind die Angaben über das Vorkommen von Dissociation dieser verschiedenen Sensibilitätsqualitäten. Herzen beobachtete z. B. in seinem Fall von Pachymeningitis hypertrophica neben der tactilen Anästbesie auch noch Kälteanästhesie bei gut erhaltener Schmerz- und Wärmeempfindung. Wallenberg beobachtete in seinem Fall von Ictus apoplecticus in der Gegend der Medulla oblongata, dass z. B. die gekreuzte Analgesie nur bis zur Clavicula hinaufreichte, während die gekreuzte Thermoanästhesie bis zum unteren Rande der Maxilla inferior hinaufstieg. Mai beobachtete in einem äbnlichen Fall eine gekreuzte Analgesie und Kälteanästhesie während die Wärmeempfindung ungestört war. Brissaud beobachtete. in einem Fall von doppelseitigem Brown-Séquard, dass die obere Grenze der Analgesie böher lag als die obere Grenze der Thermoanästhesie. Er nimmt auch für die Leitung der Temperatur- und für die Leitung der Schmerzeindrücke die Existenz verschiedener Bahnen an. v. Reusz beobachtete in einem Fall von Halbseitenläsion des Rückenmarkes in der Höhe des 3. oder 4. Dorsalwirbels: neben anderen Erscheinungen gekreuzte Thermoanalgesie mit Dissociation der Temperaturund Schmerzempfindung in der Gegend der oberen Grenze die Anästhesie die obere Grenze der Analgesie reichte nämlich bis zur Mamilla, die der Kälteanästhesie dagegen nur bis zur 7. Rippe, während noch ein gewisser Grad der Wärmeempfindung erhalten war. Wir sehen also, dass die obere Grenze der Kälteanästhesie in diesem Fall circa um zwei Inter- 
costalräume tiefer lag als diejenige der Analgesie. Schlesinger nimmt an, dass die zur Leitung der Temperatureindrücke und die zur Leitung der Schmerzeindrücke bestimmten Fasern nicht auf einer und derselben Höhe sich kreuzen mit den gleichnamigen von der anderen Seite kommenden Fasern, da die, bei Halbseitenläsion beobachtete, Thermoanästhesie und die Analgesie nicht dieselbe Ausbreitung auf der Hautoberfläche aufweisen. Nach Dejerine und Thomas kann die Art der Dissociation der spinalen Anästhesie sehr versehieden sein: so kommt z. B. eine sehr ausgesprochene Alteration der Temperaturempfindung mit relativer Integrität der tactilen Sensibilität und der Schmerzempfindung vor. In der Regel aber, sagt Dejerine, trifft man neben der Analgesie auch zugleich eine Thermoanästhesie an und beide zeigen gewöhnlich dieselbe Topographie. In den Anfangsstadien der Syringomyelie kann aber auch eine Thermoanästhesie einige Jahre dem Erscheinen der Analgesie vorausgehen - Roth. An einem anderen Ort machen Dejerine und Thomas darauf aufmerksam, dass bei Syringomyelie auch derartige Dissociation der Thermoanästhesie beobachtet wird, dass bei erhaltener Empfindung auf Kältereize die Wärmeempfindung aufgehoben sein kann (Beobachtung vou Dejerine und Tuillant, 1891). Die Ausbreitung der Wärmeanästhesie und die der Kälteanästhesie decken sich nicht immer in exacter Weise, so dass z. B. eine Seite mehr alterirt ist als die andere oder sie betreffen nicht ganz dieselben Regionen der Haut. Nach Schlesinger kommt die Wärmeanüsthesie als eine isolirte Störung häufiger vor als die Kälteanästhesie. Dieses Phänomen, sagt Schlesinger, könnte man vielleicht durch eine pathologische Steigerung der physiologischen Verhältnisse erklären, da ja die Wärmeempfindung (nach Goldscheider) im Allgemeinen weniger gut entwickelt sei als die Kälteempfindung und weil nach Oppenheim die Steigerung der normalen Erregbarkeit der Hautnerven auf Kälte viel prompter und rascher zum Bewusstsein kommt als die Verminderung der Erregbarkeit auf Wärme. Schlesinger beobachtete einen Patienten, bei dem die Kälteempfindung ganz gut erhalten war, welcher aber die Wärmereize nur als gewöhnliche Tasteindrücke auffasste. Mit der Zeit entwickelte sich bei ihm eine complete Thermoanästhesie.

Unter dem Namen der perversen oder conträren Temperaturempfindung hat Strümpell eine eigenthümliche Alteration des Temperatusinns beschrieben, die darin besteht, dass alle thermischen Reize eindeutig im Sinne ausschliesslicher Wärme- oder Kälteempfindung bewerthet werden. Alter hält die Bezeichnung als Perversität oder als Conträrempfindung für diese Störung in der Thermästhesie, im Grunde genommen, nicht für ganz richtig. Alter möchte diese Bezeichnung nur 
für diejenigen seltenen Fälle reserviren, in denen thatsächlich eine echte Perversion der Temperaturempfindung nachweisbar ist. Diese Fälle schreibt Alter - sind dadurch ausgezeichnet, dass Kälte- und Wärmeempfindung zwar erhalten sind, dass aber jede Empfindungsqualität durch den normal conträr bewertheten Reiz ausgelöst wird. Das Bewusstsein reagirt auf den Kältereiz mit Wärmeempfindung, auf den Wärmereiz mit Kälteempfindung. Solche Beobachtungen verdanken wir Schlesinger, Tumpowski und Alter. Schlesinger beobachtete eine Perversion der Temperaturempfindnag bei Syringomyelie. Diese Perversion - schreibt Schlesinger - kann entweder nur eine Qualität betreffen - es ist diès eine ziemlich häufige Anomalie - oder sie erstreckt sich in seltenen Fällen auf beide Qualitäten des Temperatursinnes. Im ersten Falle wird dann z. B. Warm für Kalt angesehen, aber Kälte richtig empfunden, während bei Kranken mit Perversion beider Unterarten der Temperaturempfindung constant Kälte die Sensation von "warm" und Hitze das Gefühl von "kalt" hervorruft. Diese Perversion betrifft nur ausnahmsweise einen grossen Hautrayon, selbst wenn die anderweitigen Temperatursimstörungen ausgedehnt sind, und persistirt zumeist wicht dauernd, lüsst sich aber oft durch Wochen selbst Monate hindurch nachweisen. Fin vollkommen befriedigende Deutung dieses Befundes giebt es bisher nicht. Man müsste nach Schlesinger am ehesten an einen veränderten Mechanismus der Umschaltung im Rückenmarksgrau denken, so dass beispielsweise die central verlaufenden Kältebahnen von den gesammten Temperaturempfindungen benutzt würden, wenn auch von der Peripherie bis zum Rückenmarksgrau die Kälte- und Wärmeempfindung isolirt fortgeleitet wurden. Tumpowski konnte eine echte Perversion der Temperaturempfindungen als ein passageres Symptom eines schweren Schubes hysterischer Erseheinungen bei einem 20 jährigen Mädchen nachweisen. Alter beobachtete dieselbe Erscheinung bei einem Paralytiker.

Zuletzt möchte ich in diesem Kapitel hier noch an die Untersuchungen von Goldscheider erinnern, aus welchem hervorgeht, dass die Kälteund Wärmewahrnehmungen an differente Sinneselemente gebunden sind, die in specifischer Function nnd Anordnung in der Haut als Kälte- und Wärmepunkte der ausschliesslichen Perception der entsprechenden Reizqualitäten dienen. Nach allen Analogien ist - nach Alter - ein unbedingtes Postulat, diesen qualitativ verschiedenen Endapparaten auch getrennte Leitungen und differente centrale Symbole zu vindiciren.

Die Untersuchungen von Max v. Frey über die Physiologie der Sinne haben gezeigt, dass eine paradoxe Excitabilität der Kältepunkte 
durch Wärme existire, dass aber in normalen Verhältnissen eine paradoxe Excitabilität der Wärmepunkte durch Kälte nichf existire.

Aus dieser Literaturübersicht habe ich vor Allem die Ueberzeugung gewonnen, dass wir auf Grund des einen oder des anderen pathologischen, wenn auch durch Autopsie constatirten Falles oder auf Grund des einen oder des anderen Thierexperimentes die Frage der Existenz im Rückenmarke besonderer Bahnen zur Leitung der verschiedenen Sensibilitätsqualitäten nicht werden lösen können. Dieses Problem ist nicht so einfach und bedarf der vielseitigsten Beleuchtung. Und die verschiedenen klinischen, pathologisch-anatomischen Fälle und experimentellen Versuche können nur einen mehr oder weniger werthvollen Beitrag zur Lösung dieser Frage liefern. In dieser Absicht erlaube ich mir meine persönlichen Beobachtungen hier anzuführen.

\section{Eigene Beobachtungen.}

Fall I. H. Z., ein 16jähriger Schneiderlehrling, bekam am 1. März 1903 während des Spazierganges im Sächsischen Garten in Warschau eine Stichverletzung in den Rücken. Sofort fiel er zu Boden und konnte sich nicht mehr allein erheben. In diesem Zustande wurde er in das Praga-Hospital gebracht auf die chirurgische Abtheilung des Chefarztes Dr. Raum. Der Assistent der Abtheilung, Dr. A. Zawadzki, constatirte in der Gegend zwischen den Schulterblättern rechts von der Wirbelsäule zwischen dem 4. und 5. Processus spinosus eine Sehnittwunde, deren verticaler, $2 \mathrm{~cm}$ langer Durchmesser, $1 \mathrm{~cm}$ von der Mittellinie entfernt war. Aus der Wunde kam eine klare, durchsichtige, etwas mit Blut untermischte Flüssigkeit heraus (wahrscheinlich Liquor cerebrospinalis). Der Kranke konnte das rechte Bein nicht in die Höhe heben; die Beuge- und Streckbewegungen im rechten Knie waren auch sehr erschwert. Die Bewegungen des linken Beines waren ungestört. Die Kniereflexe waren nicht gesteigert. Am linken Bein wurde eine Thermoanalgesie constatirt, die ungefähr bis vier Fingerbreiten oberhalb der Spina iliaca anterior superior reichte. Die taktile Sensibilitä̌ war überall intakt. Am folgenden Tage versuchte Patient aufzustehen; beim Gehversuch fiel er jedoch zu Boden; seine Beine zitterten stark. Nach einer Woche zeigte das rechte Bein nur noch eine allgemeine Schwäche. Diese Schwäche nahm aber von Tag zu Tag ab. Am 14. März 1903 wurde dieser Patient von Dr. Zawadzki in der klinischen Versammlung der Aerzte unseres Spitals demonstrirt, als ein Fall von BrownSéquard'scher Lähmung traumatischer Herkunft. In der darauf: folgenden Discussion hat ein Collego die Vermuthung ausgesprochen, ob wir es in diesem Fall nicht mit einem Syndrom von Brown-Séquard hysterischen Ursprungs zu thun haben; er stützte sich hauptsächlich darauf, dass bei diesem Patienten die rechtsseitige Parese so ungemein rasch verschwunden war. Vollkommen einverstanden mit dem Vortragenden, bestritt ich diese Ansicht, weil, wie ich mich überzeugt hatte, die Lage der oberen Grenze der Thermoanalgesie auf 
eine radiculäre Topographie der vorhandenen Sensibilitätsstörung hinwies. Später untersuchte ich den Patienten auf meiner Abtheilung ${ }^{1}$ ) am 16. und 28. März.

Bei der ersten Untersuchung constatirte ich folgendes: Patient marschirte ganz gut, die Muskelkraft des rechten Beines war nur etwas geringer als die des linken. Beim activen Auswärtswenden des rechten Fusses zeigte Patient etwas weniger Kraft als links. Die Patellarreflexe waren etwas gesteigert und merkwürdiger Weise der linke um ein wenig mehr als der rechte. Der rechte Achillessehnenreflex war etwas lebhafter ausgeprägt als der linke. Dagegen die linken Hautreflexe: der obere und untere Bauchreflex, der Cremasterreflex und der Sohlenreflex waren sehr gesteigert.

Bei einer oberflächlichen Untersuchung der Sensibilität fand ich links, in der oberen Grenze der Thermoanalgesie eine sehr deutlich ansgesprochene Dissociation der Schmerz-, der Wärme- und der Kälteanästhesie - bei normal erhaltener taktiler Sensibilität, wie das die Fig. 1 illustrirt. Die auf dem ganzen linken Beine und auf dem unteren Theil des Abdomens verbreitete Wärmeanästhesie reichte bis zur Linie $A$, die Kälteanästhesie reichte bis zur Linie $\mathrm{B}$ und die Analgesie reichte bis zur Linie C.
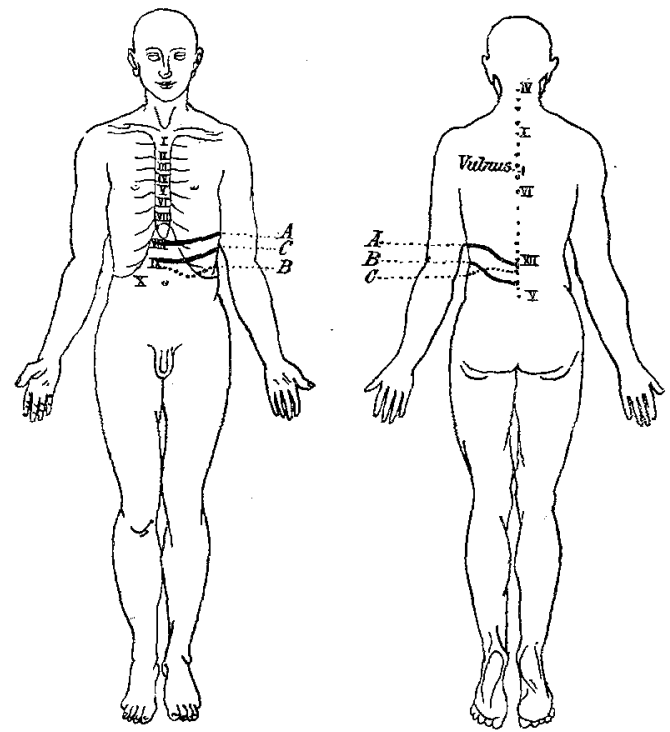

Fig. 1. Rechtsseitige Verletzung des Rückenmarkes auf der Höhe $z$ wischen dem. 4. und 5. Dorsaldornfortsatz. Thermoanalgesie des Beines und des unteren. Theiles des Abdomens links. Dissociation der Sensibilität in der Gegend der oberen Grenze dieser Thermoanalgesie: A obere Grenze der Wärmeanästhesie, $B$ der Kälteanästhesie und $\mathrm{C}$ der Analgesie.

Bei den späteren, sehr oft wiederholten Untersuchungen - bei Anwendung constanter Temperaturen - habe ich schliesslich folgendes fest-

1) Nervenabtheilung des städtischen Praga-Krankenhauses in Warschau. 
stellen können: die linksseitige Wärmeanästhesie reichte hinten bis zum 10. Processus spinosus dorsalis und vorne bis zur X. Rippe; die Kälteanästhesie reichte hinten bis zum 1. oder 2. Processus spinosus lumbalis und vorne ungefähr bis zur XI. Rippe. Die Analgesie reichte hinten bis zum 11. oder 12. Processus spinosus dorsalis and vorne bis zur VIII. Rippe. Dieses Verhältniss illustrirt uns am besten die Fig. 2. Wir sehen, dass in der Haut-

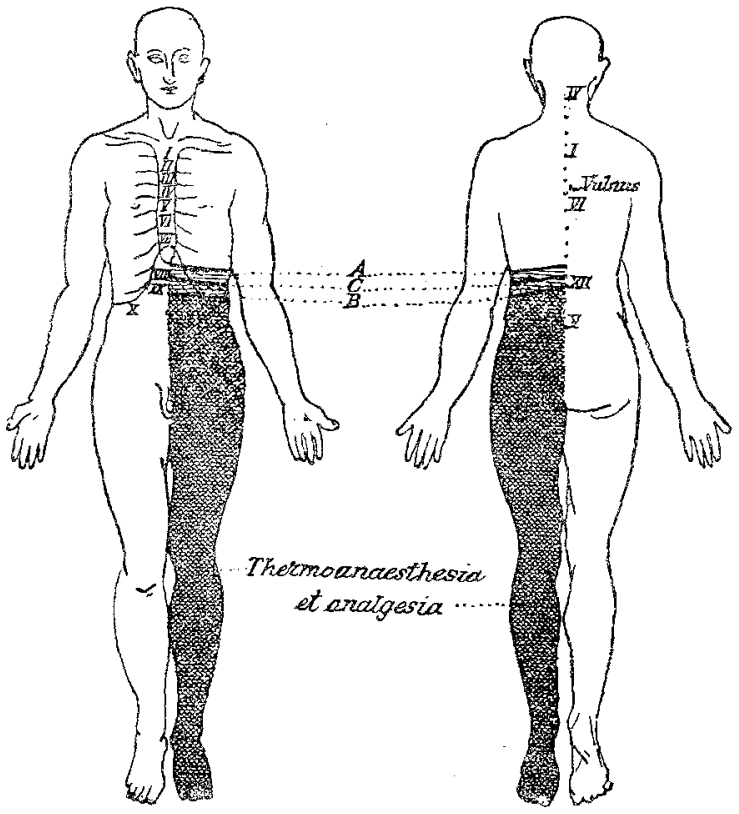

Fig. 2. Rechtsseitige Verletzung des Rückenmarkes auf der Höhe zwischen dem 4. und 5. Dorsaldornfortsatz. Thermoanalgesie des Beines und des unteren Theiles des Abdomens links. Dissociation der Sensibilität in der Gegend der oberen Grenze dieser Thermoanalgesie: A obere Grenze der Wärmeanästhesie, $\mathrm{B}$ der Kälteanästhesie und $\mathrm{C}$ der Analgesie.

zone zwischen A und B die Kälteempfindung erhalten, während die Wärmeempfindung erloschen war und in der Hautzone zwischen $\mathrm{B}$ und $\mathrm{C}$ die Kälteempfindung erhalten war, dagegen die Schmerz- und Wärmeempfindung fehlte. Bei der Anwendung von verschiedenen Temperaturen fand ich gemeinschaftlich mit meinem Assistenten, Dr. Sokolowski, dass die Entfernung der beiden Linien $\mathrm{A}$ und $\mathrm{B}$ am grössten, d. h. dass die Dissaciation der Kälte- und der Wärmeempfindung am ausgebreitetsten ist, wenn man zur Untersuchung die Temperaturen $0^{\circ}$ and $+50^{\circ}$ anwendete. Ich benutzte daze ganz gewöhnliche mit auf gewünschte Temperatur erwärmtem Wasser gefüllte Probirröhrchen. Die Höhe der Temperatur gab uns ein dünner in das Wasser getauchter CelsiusThermometer an. Ich berührte mit dem Probirröhrchen von unten nach oben gehend die Hautoberfläche und nahm diejenige Stelle für die obere Grenze der 
Thermoanästhesie an, wo der Patient anfing, Wärme- oder Kälteempfindung zu äussern. Zur Herstellung der unterhalb $0^{0}$ gelegenen Temperaturstufen füllte ich die Probirröbrchen mit einer Mischung von gepulvertem Eis und Salz in versohiedener Proportion. Nachdem ich die Lage der Gronzen A und B genau bestimmt hatte, fing ich nun an, ganz versohiedene Temperaturen anzuwenden. Das dabei am 21. August 1903 erhaltene Resultat illustriren uns die Fig. 3 und 4. Bei der Anwendung von Temperaturen $+60^{\circ},+70^{\circ},+80^{\circ}$,
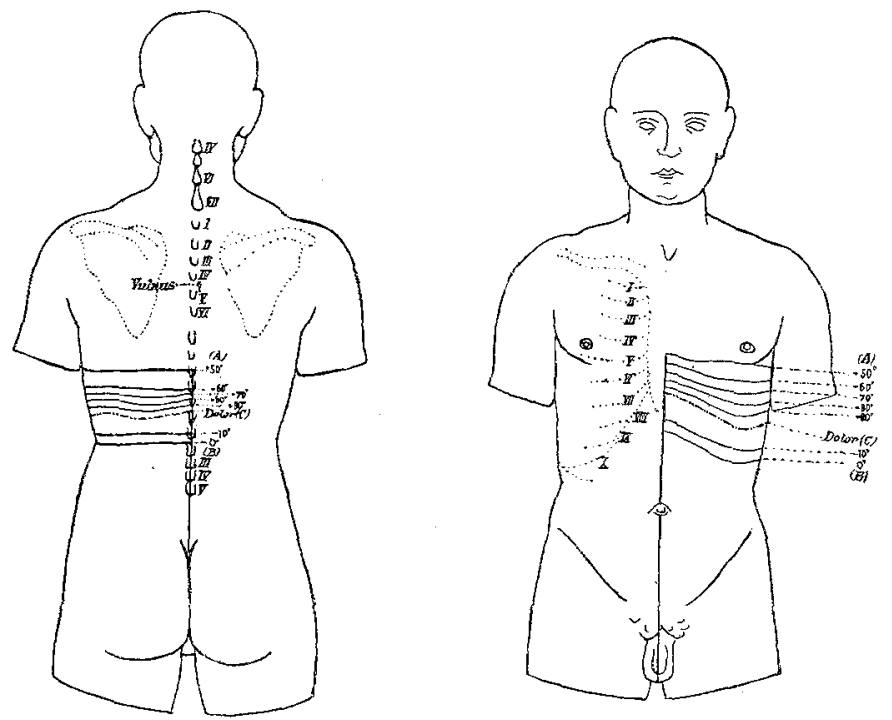

Fig. 3 und 4. Rechtsseitige Verletzung des Rückenmarkes auf der Höbe zwischen dem 4. und 5. Processus spinosus dorsalis. A obere Grenze der Anästhesie auf $+50^{\circ}$ Celsius, $B$ auf $0^{\circ}$ und $\mathrm{C}$ obere Grenze der Analgesie. Zwischen A und $\mathrm{C}$ liegen die oberen Grenzen der Anästhesien auf $+60^{\circ},+70^{\circ},+80^{\circ}$, $+90^{\circ}$. Zwischen $B$ und C liegen die oberen Grenzen der Anästhesie - 50, $-10^{\circ}$ u. S. W.

$+90^{\circ}$ u. s. w. kommt die obere Grenze der Thermoanästhesie immer tiefer zu liegen und nähert sich der oberen Grenze der Analgesie C. Bei der Anwendung der unterhalb $0^{0}$ liegenden Temperaturen $-5^{0},-10^{\circ},-15^{\circ}$ u. s.w. komm die obere Grenze der Thermoanästhesie immer böher zu liegen, indem sie sich der oberen Grenze der Analgesie $\mathrm{C}$ von unten her nähert.

Andererseits aber liegen die oberen Grenzen der Temperaturen $+10^{\circ}$, $+20^{\circ},+30^{\circ}$ und $+40^{\circ}$ ebenfalls zwischen den Linien $A$ und $B$, so dass z. B. die obere Grenze der Unempfindlichkeit auf $+10^{\circ}$ ungefähr auf derseloen Höhe mit der oberen Grenze der Unemptindlichkeit auf $-10^{\circ} \mathrm{zu}$ liegen kommt und z. B. die obere Grenze für $+40^{\circ}$ ungefähr auf der gleichen Höhe mit der oberen Grenze für $+60^{\circ}$ zu liegen kommt. Nor für die Temperatur $+30^{\circ}$ (annähernd die Temperatur der Hant) lässt sich keine bestimmto 
Grenze constatiren. Die oberen Grenzen der Unempfindlichkeit für die Temperaturen $+10^{\circ},+20^{\circ},+30^{\circ},+40^{\circ}$ u. s. w. bis $+50^{\circ}$ habe ich in die Zeichnung nicht aufgenommen, damit die Zeichnung nicht an Klarheit verliere.

Noch eine andere in diesem Fall beobachtete Thatsache verdient volle Beachtung - das ist die Beziehung zwischen der oberen Grenze der Anästhesie und dem Sitz der Rückenmarksläsion. Wie wir sahen, liegt die Läsion zwischen dem 4. und 5. Dorsaldornfortsatz, die obere Grenze der Thermoanästhesie für $+50^{0}$ liegt um 6 Dornfortsätze, für $0^{0}$ um 10 Dornfortsätze tiefer. Die obere Grenze der Analgesie liegt zwisehen den Linien B und A und zwar um 7 Dornfortsätze unterhalb der Rückenmarksläsion. Wenn dieses Verhältniss constant wäre, könnte man ja umgekehrt aus der Lage der oberen Grenze der Thermoanalgesie den Sitz der Rüokenmarksläsion bestimmen. Wenn die obere Gronze der Thermoanalgesie auf der Höhe des 11. und 12. Dorsaldornfortsatzes liegen würde, müsste man die Läsion des Rückenmarkes aư der anderen Seite ungefähr auf der Höhe zwischen dem 4, und 5. Dorsaldornfortsatz vermuthen. Wenn dies wirklich immer sich so verhalten würde, bätten wir in den Sensibilitätsstörungen einen ausgezeichneten diagnostischen. Fingerzeig zur Bestimmung der Localisation eines krankhaften Processes, welcher z. B. aus dem Knochen oder aus dem Periost des Canalis vertebralis ausgehend auf das Rückenmark übergegangen ist und speciell diejenige Stelle der seitlichen Peripherie des Rückenmarkes lädirt hat, wo gerade die Bahnen der Schmerzund Temperaturempfindung durchgehen. Aus der Lage der oberen Grenze der Thermoanalgesie könnten wir also den Sitz der Rückenmarksläsion bestimmen.

Aus dem allen, was ich hier angefüllrt habe, sehen wir, dass wir es in unserem Falle mit einer ganz kleinen und sehr beschränkten Läsion des Rückenmarkes zu thun haben müssen.

Hente - 6 Monate nach dem Unfall ${ }^{I}$ - zeigt Patient ausser der linksseitigen Thermoanalgesio gar keine anderweitigen nervösen Störungen, er arbeitet wieder in seinem Fach als Schneider. Alle anderen Störungen, die er früher zeigte, sind spurlos verschwunden.

Wie können wir uns nun die vorhandene Thermoanästhesie erklären? Auf welchem Wege ist sie entstanden? Durch eine Blutung in die grane Substanz des Rückenmarkes (centr. Hämatomyelie) - die ein College während der diesbezüglichen Discussion in der Warschauer Aerztegesellschaft vermuthet hat lässt sich die gekreuzte Thermoanästhesie in diesem Falle nicht erklären. Bei centraler Hämatomyelie hätten wir eine nur auf eine bestimmte Stelle der Hautoberfläche beschränkte Sensibilitätsstörung in Form einer halben Zone oder eines halben Gürtels. Unsere Thermoanästhesie dagegen ist eine complete, die eine ganze Körperhälfte einnimmt, d. h. von den Zehen bis zu den Linien A, B, C hinaufreicht. Auch kann man die in diesem Fall gebliebene gekreuzte Thermo-

1) Ich untersuchte den Patienten noch einmal am 11. Mai 1904 und constatirte bei ihm dieselbe Thermoanästhesie wie früher, ohne die geringste Aenderung. 
analgesie nicht durch eine Compression der weissen Substanz, nämlich der seitlichen Peripherie des Rückenmarkes, wo die zur Leitung der Temperatur- und Schmerzempfindungen bestimmten Bahnen vermuthlich verlaufen, erklären. Wenn ein Extravasat die Ursache der Thermoanästhosie gewesen wäre, müsste die Thermoanästhesie schon lange verschwunden sein, weil das Extravasat schon längst aufgesaugt wäre. Es unterliegt gar keinem Zweifel, dass die Thermoanalgesie bei meinem Patienten nur durch eine Unterbrechung derjenigen langen Bahnen des Rückenmarkes hervorgerufen worden ist, welche zur Leitung der von der contralateralen Körperbälfte kommenden Schmerz- und Temperatureindrücke bestimmt sind. Und da der Patient jetzt, abgesehen von der gekreuzten Thermoanalgesie, vollständig gesund ist, müssen wir annehmen, dass die Stichverletzung des Rüekenmarkes nur eine ganz oberfächliche war, d. h. nur die Peripherie des Rückenmarkes betraf. Und da der Stich zwischen 2 Wirbeln in einer Entfernung von $1 \mathrm{~cm}$ von der Mittellinie stattgefunden hat, liegt es sehr nahe anzunehmen, dass eben nur die seitliche Peripherie des Rückenmarkes verletzt wurde. Und da in unserem Fall als einziges und isolirtes Symptom nur noch die gekrenzte Thermoanästhesie geblieben ist, so müssen wir annehmen, dass nur die langen schmerz- und temperaturleitenden Bahnen anatomisch unterbrochen wurden und dass dieselben eben gerade in der seitlichen Peripherie des Rückenmarkes resp. des Seitenstranges verlaufen müssen. Die anfangs constatirten motorischen Störungen in dem rechten Beine waren abhängig vom Blatextravasat und vom collateralen Oedem, welche im Rückenmarke in der Umgebung der Verletzungsstelle jedenfalls entstanden sind. Diese Störungen bildeten sich zuräck, sobald das Blutextravasat und das collaterale Oedem resorbirt wurden.

Jetzt gehe ich zur Beschreibung des zweiten Falles, der mit dem angeführten manches gemeinsam hat.

Fall II. L. W., ein 16jähriger Schneidergeselle, welcher niemals syphilitisch inficirt war und auch keine Zeichen der Syphilis hereditaria oder der Tuberculole darbot, erkrankte im Dezember 1900 an Polyarthritis. 4 Wochen nach Ablauf dieser Krankheit verspürte er Schmerzen und eine gewisse Steifigkeit im Nacken. Allmählig verschwanden die Schmerzen, die Naekensteifigkeit blieb aber bestehen; er konnte den Kopf nicht mehr frei hin and her bewegen. Im Juni 1901, also 6 Monate später, traten die ersten Symptome einer Compression des Cervicalrückenmarkes auf; es stellte sich eine Steifigkeit im linken Arm, in der rechten Seite des Abdomens und im rechten Bein ein und 14 Tage später auch im rechten Arm, in der linken Thoraxbälfte und im linken Bein. Nach Verlauf weiterer 14 Tage verlor Patient allmählig die Bewegung in den oberen und später auch in den unteren Extremitäten, so dass sich im Laufe von circa 2 Monaten eine vollständige Paralyse aller vier Extremitäten und des Abdomens entwickelt hat. In diesem Zustande wurde Patient am 16. September auf meine Abtheilung gebracht. Bei der Untersuchung wurde folgendes festgestellt: der Kopf des Patienten ist etwas nach rechts rotirt und etwas gegen die linke Schulter geneigt. Es besteht Nackensteifigkeit. Die Kopfbewegungen sind sehr besehränkt und erschwert und ver- 
ursachen dem Patienten grosse Schmerzen; die einzige mögliche active Bewegung ist eine ganz kleine Bewregung des Kopfes nach vorne, die er auch beim Sprechen oft unaufgefordert ausführt, um sich das Sprechen zu ermöglichen, sonst ist das Sprechen und auch das Athmen sehr erschwert. Schlucken konnte Patient gut, die Zunge ausstrecken konnte er auch. Durch passive Bewegungen konnte man die pathologische Lage des Kopfes noch dentlicher machen; die Bewegungen behufs Correction dieser Lage waren dagegen unmöglich und verursachten grosse Schmerzen. Die oberen und unteren Extremitäten befanden sich im Zustande vollständiger Paralyse. Bei passiven Bewegungen stiess man auf bedeutende Rigidität der Muskeln. Andererseits dagegen sah man oft spontane plötzlich auftretende, rasche, vom Willen ganz unabhängige, schmerzhafte Contractionen in verschiedenen Muskeln auftreten. Oft ganz vom Willen unabhängig kam es plötzlich zu einer so heftigen Bewegung beider Beine in den Hüft- und Kniegelenken, dass die Kniee dio Brust. berührten und Patient im Bett rom Kissen hinunterrutschte. Gleichzeitig kam es dabei anch zu einer Versteifung der Arme, zur maximalen Extension derselben; die Arme näherten sich an einander und wurden dabei so stark pronirt, dass die Handflächen nach auswärts gedreht waren. In diesem Zustande der Torsion, wo der ganze Körper wie in einem Knäuel zusammengewickelt war, empfand Patient unerträgliche Schmerzen in der Brust und in den Knieen. Diese Bewegungen traten gewöhnlich ganz spontan ohne sichtbaren Grund auf, sie konnten jedoch auch auf folgende Weise hervorgerufen werden: dazu genügte z. B., dass man die Handfläche mit einem Bleistift bestrich. Alle Hautund Sehnenreflexe waren ausserordentlich gesteigert. Babinski war beiderseits vorhanden. Der Fuss- und Händeclonus waren sehr ausgesprochen. Alle Augenblicke wurde der Patient von einem kurzdauerndem Schütteln oder Zittern befallen, das aber auch nicht von dem geringsten Kältegefühl begleitet war. Es bestand ausserdem noch: Incontinentia urinae, Retentio alvi und starker Priapismus. Störungen der taktilen Sensibilität (auf das eventuelle Vorhandensein von Störungen anderer Sensibilitätsqualitäten habe ich leider nicht geprüft) war auf der ganzen Körperoberfläche verbreitet, wie wir dies aus der Fig. 5 sehen können.

Die Behandlung in diesem Falle bestand in Verabreichung von Jodkalium innerlich und Anwendung von Bädern, Massage und passiver Gymnastik. 4 Monate lang blieb der Zustand stationär. Auf ein Mal ohne nachweisbaren Grund erkrankte der Patient an acuter exsudativer linksseitiger Pleuritis. Sein Zustand war drohend. Während der 5 . Woche vom Beginn dieser neuen Erkrankung fingen an die motorischen und sensiblen Störungen an den Extremitaten allmählig zurückzugehen. Das erste Zeichen war eine ganz minimale Bewegung der Zehen. Im Laufe der nächsten 5 Monate machte die Besserung so rapide Fortschritte, dass im Januar 1902 Patient schon marschiren konnte und z. B. mit der rechten Hand (welche noch immer stärker ergriffen war als die linke) mit einer Scheere Etiquetten ans Papier für die Spitalapotheke herausschneiden konnte. 


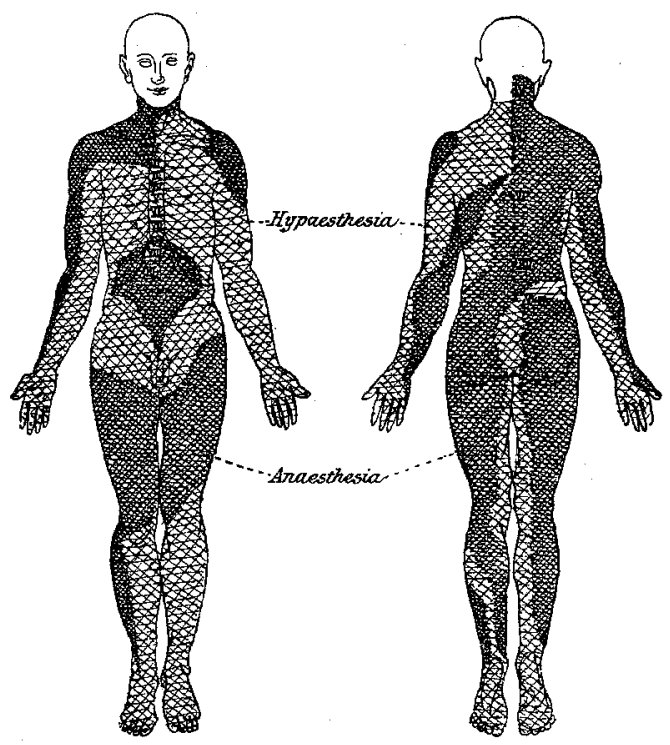

Fig. 5. Ein Fall von Meningomyelitis cervicalis superior e compressione, entstanden in Folge eines chronisch entzündlichen Processes, welcher den Atlas und speciell die Gelenke zwischen Atlas und Epistropheus ergriffen und zur einseitigen pathologischen Rotationsluxation des Atlas von Kocher geführt hat. Schmerzen im Nacken und Nackenstarre. Spastische Paralyse aller vier Extremitäten, des Thorax und des Rúmpfes. Steigerung der Sehnen- und Hautreflexe. Reflexe von Babinski. Rasch auftretende Spontanbewegungen: Torsion und Extension der Arme und Bewegung der Beine. Incontinentia urinae, Retentio alvi, Priapismus, Hypästhesie auf der ganzen Hautoberfläche mit Ausnahme des Kopfes; stellenweise complete Anästhesie. Vollständige Heilung im Verlauf von 12 Monaten. Es blieb am 31. Januar 1903 nur noch eine linksseitige Thermoanalgesie bestehen (siehe Fig. 10).

Gegenwärtig füblt sich L. W. ganz gesund und verdient sich selbst sein Brod. Bei der Untersuchung findet man jedoch folgendes: der Kopf befindet sich in einer Schiefstellung, das Gesicht ist etwas nach rechts gedreht und der ganze Kopf auf die linke Schulter hinüber gelenkt, wie wir dies aus der Fig. 6 leicht ersehen können. Die Rotation des Kopfes nach links und die Neigung gegen die rechto Schulter sind heute noch sehr beschränkt und schmerzhaft. Die Bewegungen der rechten Hand sind nicht so frei und nicht so präcis wie die der linken; die Muskelkraft der rechten Hand ist auch um ein klein wenig geringer als die der linken Hand; auch das rechte Bein ist etwas schwächer als das linke. Diese motorischen Störungen können jedoch nicht so bedeutend sein, wenn man bedenkt, dass Patient gut gehen kann und wieder in seinem Fach - wie das oben schon erwähnt wurde - arbeiten kann. Die Pupillen sind gleich weit und ihre Reaction auf Licht und Accommodation ist normal. Die Sehnenreflexe an den Extremitäten sind gesteigert rechts mehr als links; die Hauptreflexe dagegen sind links mehr gesteigert als rechts. Der 
Babinski'sche Reflex ist heute nur noch rechts vorhanden. Die taktilo Sensibilität ist auf der ganzen Körperoberfläche wieder zurückgekehrt. . Nur auf dem

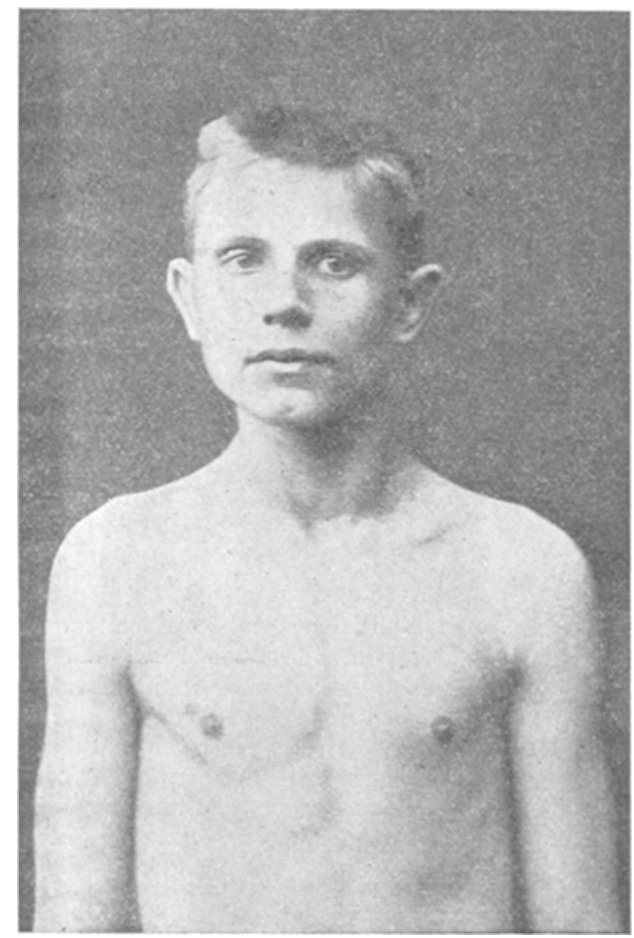

Fig. 6. Ein Fall Meningomyelitis cervicalis superior e compressione mit Hemithermoanalgesie. Pathologisehe Kopfhaltung in Folge einer Dislociation der oberen Halswirbel bei einseitiger pathologischer Rotation des Atlas von Koeher.

linken Bein und auf der linken Seite des Abdomens besteht eine vollständige Thermoanalgesie. Die Functionen der Harnblase und des Rectums sind auch normal.

Wenn wir den ganzen Verlauf dieser Krankheit in's Auge fassen und hauptsächlich die Thatsache, dass die Krankheit mit Schmerzen im Nacken und Nackenstarre begounen hat, dass die ersten Symptome einer Affection des cervicalen Rückenmarkes erst 6 Monate später aufgetreten sind und dass dann im Laufe von 3 Monaten diese Störungen allmälig bis zu einer vollständigen Paralyse des Rumpfes und der Extremitäten geführt haben: wenn wir andererseits die heftigen Kopfschmerzen neuralgischen Charakters, über welche Patient geklagt hat, die Beschleuni- 
Zum Studium der Dissociation der Temperatur- u. Schmerzempfindung. 981

gung des Pulses und der Athmung, die Störungen der Sphineteren in Betracht ziehen, müssen wir zu der Ueberzeugung gelangen, dass wir es in diesem Fall mit einem entzündlichen Process der Wirbelsäule in der

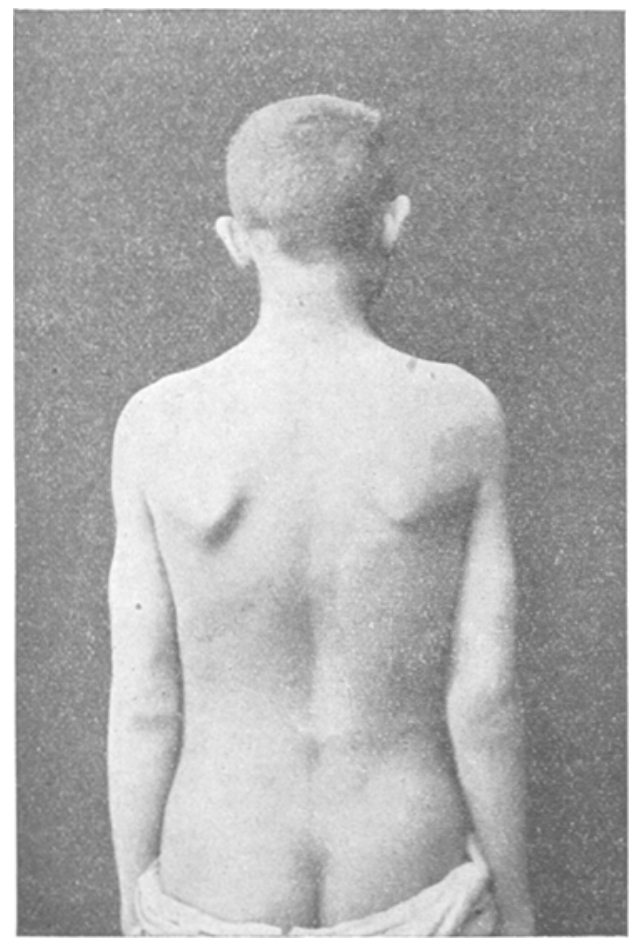

Fig. 7. (Nähere Bezeichnung s. Fig. 6.)

Gegend des Nackens zu thun hatten, welcher eine Compression des Rückenmarkes auf dieser Höhe bedingt und zur Meningomyelitis cervicalis superior e compressione geführt hat.

In Anbetracht der sehr charakteristischen pathologischen Lage des Kopfes (Drehung mach rechts und Neigung nach links), in Aubetracht dessen, dass es dem Patienten viel leichter war, diese pathologische Lage des Kopfes noch mehr zu accentuiren, als sie anfzuheben und hauptsächlich in Anbetracht dessen, dass der Chirurg, Dr. Malis zewski, bei der Untersuchung des Pharynx in der oberen Partie der hinteren Pharynxwand eine deutliche Prominenz constatirt hat, auf welcher der Finger, bei der Bewegung von oben wach unten, etwas nach hinten rutschte - habe ich die Vermuthung geäussert, dass wir es hier mit einer 
"einseitigen pathologischen Rotationsluxation des Atlas von Kocher" zu thun haben. Und die Anwendung der Röntgen-Strahlen, die am 6. October 1902 von Dr. Barszczewski mit der grössten Sorgfalt durchgeführt wurde, bestätigte diese Vermuthung. Die Fig. 8 stellt uns die Radiographie der cervicalen Partie der Wirbelsäule bei unserem Patienten dar. Beim Vergleich dieser radioskopischen Aufnahme mit der radioskopischen Aufnahme der Wirbelsäule eines gesunden Menschen - Fig. 9 -, die mir freundlichst von Dr. Barszczewski zur Verfügung gestellt wurde, sehen wir, dass bei unserem Patienten eine deutliche Kyphose im oberen Theil der cervicalen Partie der Wirbelsäule vorhanden ist. Die Deviation der Wirbelsäule bildet nach hinten einen deutlichen Winkel (Fig. 8).

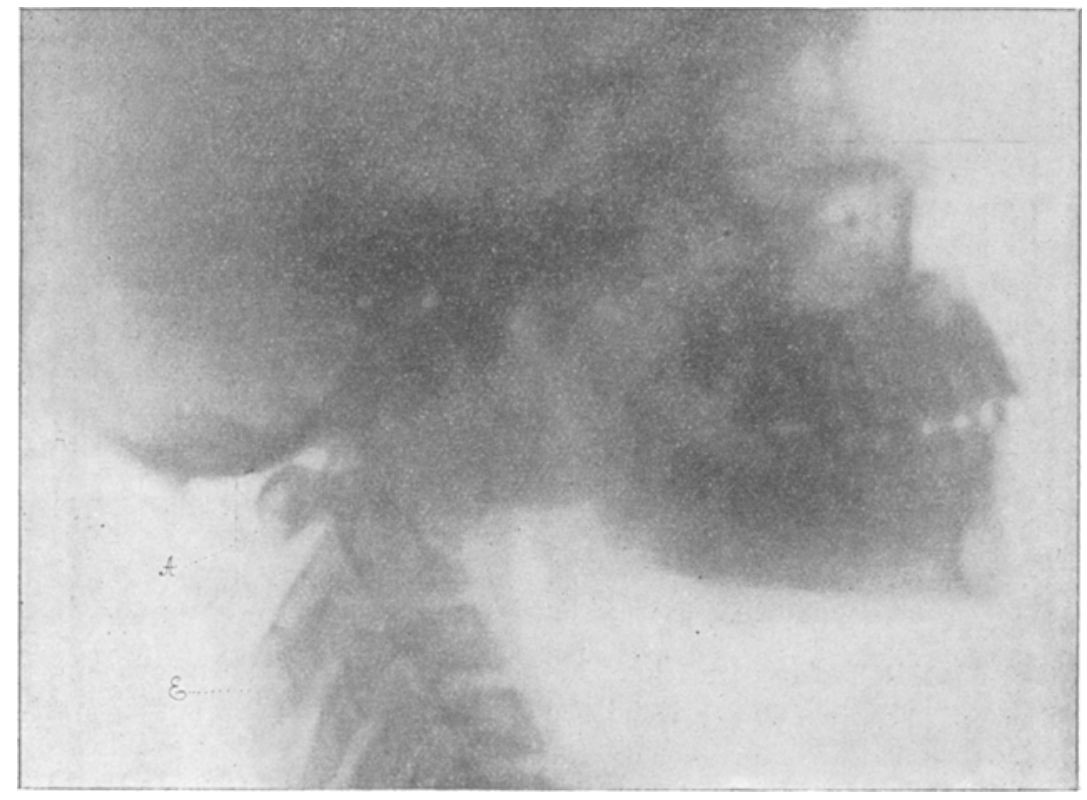

Fig. 8. Radiographia lateralis sinistra. Positio sagittalis. Dist. $=0,44$. Punctum incideus: Processus mastoideus dexter. Juvenus aetate XVII Annorum. Dr. Barszewski. - Einseitige pathologische Rotationsluxation des Atlas von Kocher. -- Meningomyelitis cervicalis superior e compressione.

Da in der Anamnese durchaus keine Anhaltspunkte zur Annahme eines überstandenen Traumas gefunden werden konntell, liegt es sehr nahe, anzunehmen, dass wir es in diesem Falle nicht mit einer traumatischen, sondern mit einer pathologischen Luxation resp. Dislocation des Atlas zu thun haben, die in Folge eines krankbaften Processes in den 
Wirbeln oder in den Intervertebralgelenken entstanden ist. Es ist sehr wahrscheinlich, dass der entzündliche Process sich hauptsächlich zwischen dem Atlas und dem Epistropheus localisirt hat, die vertebralen Gelenkflächen und die Ansatzstellen der Ligamente vernichtet oder in der Weise verändert hat, dass es zu einer Erschlaffung des ganzen Gelenkapparates und schliesslich zu einer pathogischen Dislocation des Atlas gekommen ist. Dass der Atlas jetzt noch sehr verdickt und in seiner

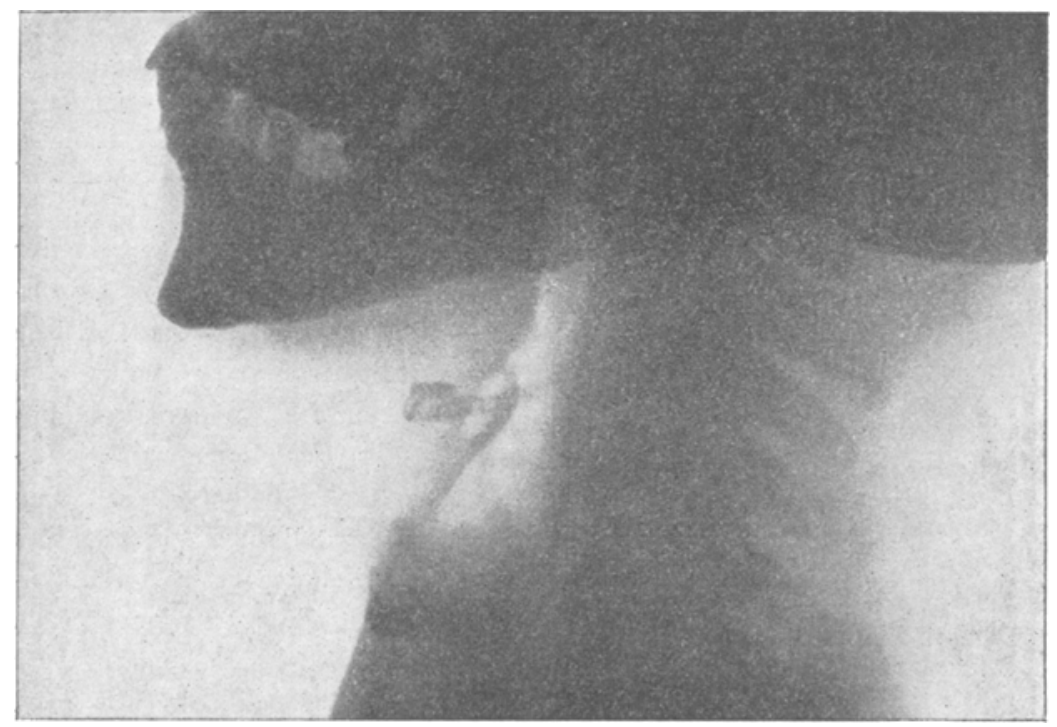

Fig. 9. Radiographia lateralis dextra. Normale Wirbelsäule. Dr. Barszewki. Configuration bedeutend verändert ist, dies sehen wir in der Fig. 8: erstens spricht dafür der weite, nicht den normalen Verhältnissen entsprechende Abstand des Atlas von dem Os occipitale und die Radioskopie des Atlas selbst - wir sehen ja deutlich eine bedeutende Verdickung an der Stelle des vorderen Atlasbogens. In Folge dieser zweifellosen Dislocation des Atlas auf dem Epistropheus kam es zu einer derartigen Verschmälerung des Canalis vertebralis, dass es zu einer Compressionsmeningomyelie gekommen ist. Die Einengung des Canalis vertebralis war nicht so bedeutend, dass sie die ganze nervöse Leitungsfähigkeit des Rückenmarkes definitiv unterbrochen hätte, aber sie war genügend, um alle Symptome der Compression des Rückenmarkes hervorzurufen, die ja wahrscheinlich durch Störungen in der Circulation des Blutes und hauptsächlich der Lymphe und durch die dabei zu Stande kommende Lymphstauung und Oedem (Schmaus) bedingt sind. Die 
Lymphstauung und das Oedem des Rückenmarkes vernichten die Nervenzellen und die Nervenfasern nicht so leicht. Sie können lange bestehen bleiben, ohne eine Entzündung und Sklerose des Rückenmarkes hervorzurufen.

Wie können wir uns jetzt die Besserung bei unserem Patienten und den Rückgang aller Symptome einer Rückenmarkscompression bei ihm erklären, wenn - wie dies die radioskopische Untersuchung gezeigt hat - die Bedingungen der pathologischen Luxation oder Dislocation sich nicht geändert haben. Wir können uns das nur durch ein allmäliges Zurücktreten der Lymphstauung und des Oedems erklären.

Was die ganz geringe, heute noch bestehende spastische Parese des rechten Vorderarmes und der rechten Hand anbelangt, können wir dieselbe nicht etwa durch eine Zerstörung oder Affection der grauen Substanz des Rückenmarkes erklären, weil die primären Centren der Vorderarm- und Handmuskeln nicht auf der Höhe des 1. und 2., sondern auf der Höhe des 6. und 7. Halswirbels gelegen sind. Diese spastische Parese lässt sich nur durch die noch bestebende Compression der weissen Substanz der rechten Rückenmarkshälfte auf der Höhe des 1. und 2. Halswirbels erklüren und zwar der dort gelegenen rechtsseitigen Pyramidenseitenstrangbahn. ${ }^{1}$ ) In Anbetracht dessen jedoch, dass diese rechtsseitige Parese der Extremitäten sich allmählich bessert, sind wir gezwungen anzunehmen, dass die Compression der rechten Rückenmarkshälfte resp. die Lymphstauung und das Oedem in der rechten Rückenmarkshälfte sich allmählich zurückbilden. Bei der Abnahme der Compression des Rückenmarkes, einer Compression, die durch einen, von den Wirbeln ausgehenden entzündlichen Process bedingt ist, muss die Lymphstauung und das collaterale Oedem zuerst in der Gegend des Canalis centralis verschwinden und sich am längsten in der Peripherie des Rückenmarkes halten. Wir werden auf diesen Umstand noch einmal zurückkommen bei der Erklärung der bei unserem Patienten heute bestehenden gekreuzten Thermoanalgesie. Denn ausser der heute noch bestehenden Schwäche der rechten Extremitäten, der Steigerung der Sehnenreflexe rechts, des Vorbandenseins des Babinski'schen Reflexes rechts, der Steigerung der Hautreflexe links constatirte ich am 19. März 1903

1) Ich möchte bei dieser Gelegenheit auf ein Detail aufmerksam machen: als vor einem Jahre beide Beine paralysirt waren, sahen wir den Babinskischen Reflex auf beiden Seiten. Heute lässt er sich nur noch auf der rechten Seite hervorrufen - im Einklang damit, dass heute nur noch die rechte Pyramidenseitenstrangbahn kranlihaft verändert ist. Dieser Fall zeigt uns deutlich die Bedeung des phénomène des orteils ron Babinski. 
die Anwesenheit einer linksseitigen Thermoanalgesie, welche ungefähr bis zur Höhe der 1. Rippe hinaufreichte, wie dies Fig. 9 zeigt. Das Ensemble aller dieser Symptome stellt ein Syndrom von B rown-Séquard dar, welches ein Ausdruck einer rechtsseitigen Affection des Rückenmarkes auf der Höbe des 1 . Halswirbels ist. Diese Laesion besteht in einer heute noch vorhandenen Compression des rechten Seitenstranges. Denn die geringe spastische Parese der rechten Extremitäten können wir nur durch eine Lymphstauung und durch ein collaterales Oedem des rechten Pyramidenseitenstranges erklären. Da aber diese Parese allmählich verschwindet, müssen wir annehmen, dass die Compression der Pyramidenfasem auch abaimmt. Da aber die Lymphstaung zuerst. im Centrum des Rückeumarkes und erst nachher von der Peripherie des Rückenmarkes schwindet - wenigsteus in denjenigen Fällen, in welchen die Ursache der Compression des Rückenmarks von der inneren Wand des Canalis vertebralis ausgeht - müssen wir annehmen, dass die Lymphstauung und das Oedem der seitlichen Peripberie des rechten Seitenstranges selbst noch stärker ansgesprochen ist als die der Pyramidenseitenstrangbahn. Wie kann man sich un die gekreuzte Thermoanalgesie in diesem Fall erklären?. Nur indem man annimmt, dass die Leitung der von der linken Körperhälfte kommenden Temperatur- und Schmerzeindrücke von einer Bahn besorgt wird, die im contralateralen (rechten) Seitenstrange liegt und zwar in seiner lateralen Pexipherie.

Auch in diesem Fall beobachtete ich bei oberflächlicher Untersuchung in der Gegend der oberen Grenze der Anaesthesie eine Dissociation der Sensibilität, wie sie Fig. 10 darstellt.

Jedoch bei näkerer spảterer Untersuchung, nater Anwevdung constanter und bestimmter Temperaturen coustatirte ich, dass die obere Grenze der Wärmeanästhesie A höher lag als die obere Grenze der Kälteanästhesie B - siehe Fig. 11.

Auch in diesem Fall benutzte ich bei der Untersuchung verschiedene Temperaturen und fand am 30. Januar 1903, wie wir aus den Fig. 12 und 13 sehen, dass die obere Anästhesiegrenze für $+50^{\circ}$ bis zum 6. Processus spinosus dorsalis, für $0^{D}-$ bis zum 8. Processus spinosus und für Schmerz - bis zum 7. Processus spinosus hinaufreicht. Vorne ging die Grenze für $+50^{\circ}$ ungefähr bis zur 5 ., für $0^{\circ}-$ bis zur 7. und für Schmerz bis zur 6. Rippe. Die oberen Grenzen der Anästbesien für $+60^{\circ},+70^{\circ},+75^{\circ}$ etc. lagen immer tiefer, zwischen $\mathrm{A}$ und $\mathrm{C}$, und für $-5^{\circ},-10^{\circ}$ etc. immer höher, zwischen $\mathrm{B}$ und $\mathrm{C}$, und näherten sich allmählich der Linie $\mathrm{C}$.

Wie wir sehen, haben wir in beiden Fällen von Verletzung und von Compressionsmyelitis des Rükenmarkes fast identisehe Störungen 

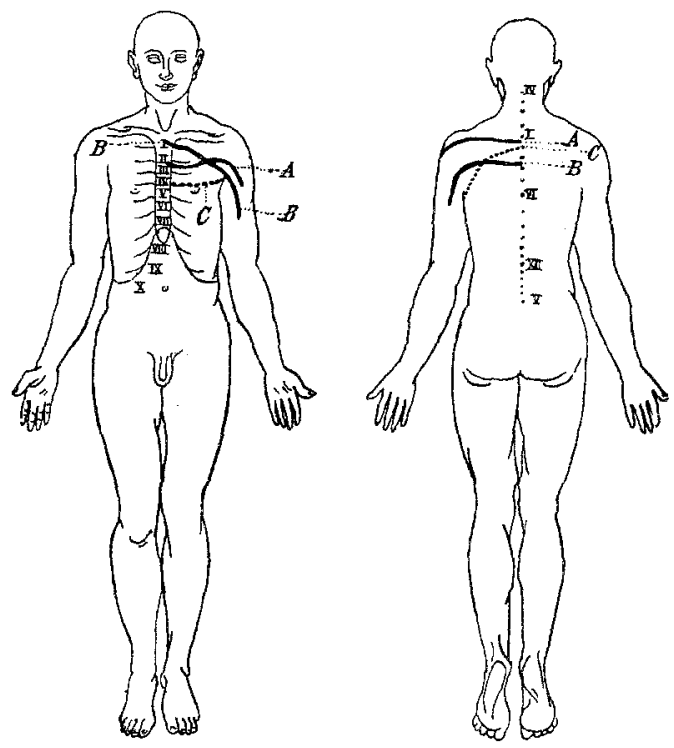

Fig. 10. Dissociation der Sensibilität in der Gegend der oberen Grenze der Thermoanästhesie - bei oberflächlicher Untersuchung.
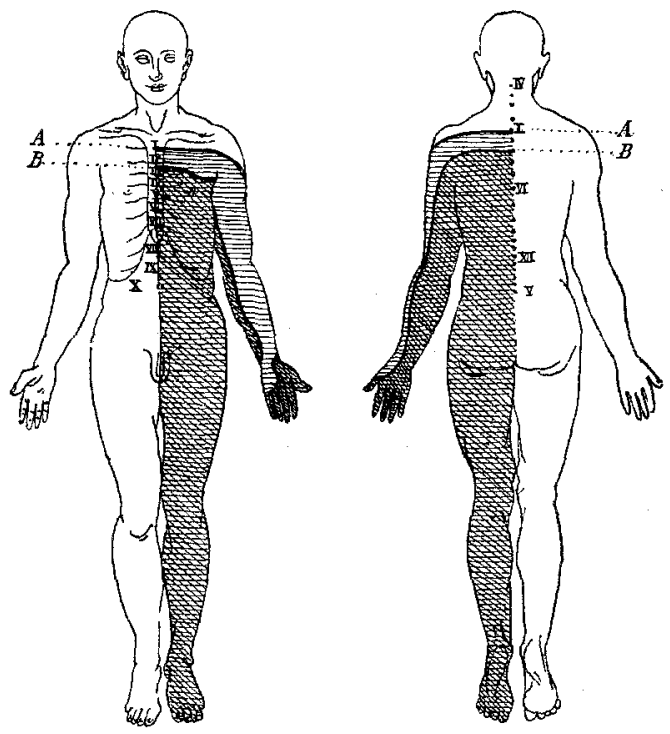

Fig. 11. Ein Fall von Meningomyelitis superior e compressione: leichte Affection der seitlichen Peripherie des Rüickenmarkes rechts auf der Höhe des Atlas. Gekreuzte Thermoanalgesie links. Dissociation der Thermosensibilität in der Gegend der oberen Grenze die der Thermuanalgesie: A obere Grenze der Anästhesie für Wärme-, B für Kältereize. 

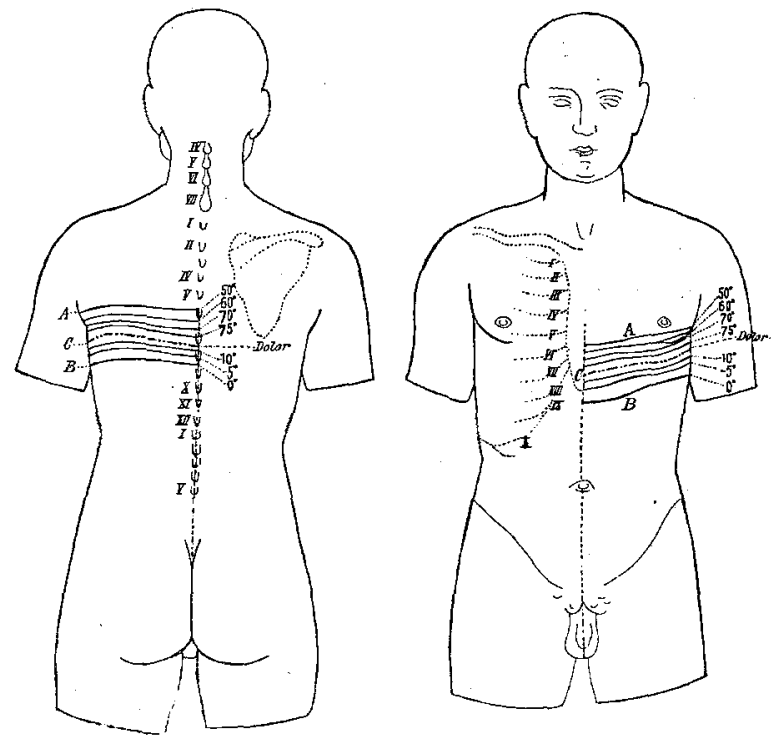

Fig. 12 und 13. Ein Fall von Meningomyelitis cervicalis superior e compressione in Folge einer pathologischen Rotationsluxation des Atlas. Thermoanalgesia sinistra. Dissociation der Sensibilität in der Gegend der oberen Grenze der Thermoanalgesie: A obere Grenze der Anästhesie für $+50^{\circ}, \mathrm{B}$ für $0^{\circ}$ und $\mathrm{C}$ für Schmerz. Zwischen A und $\mathrm{C}$ liegen die oberen Grenzen der Anästhesien für $+60^{\circ}$, $+70^{\circ}$, $+75^{\circ}$ etc., zwischen $B$ und $C$ die oberen Grenzen der Anästhesien für $-5^{0},-10^{0}$ etc.

der Sensibilität constatirt, nämlich eine gekreuzte Thermoanalgesie und eine sehr charakteristische Dissociation derselben in der Gegend ihrer oberen Grenze. In beiden Fällen sass die Affection des Rückenmarks rechts, in beiden Fällen war Thermoanästhesie links. Diese Fälle unterscheiden sich nur durch die verschiedene Localisation des krankhaften Processes, bei W. (Fall II) bestand eine Compression des Rückenmarks auf der Höhe der beiden obersten Halswirbel, bei Z. (Fall I) war eine Stichverletzung des Rückenmarks zwischen dem 4. und 5. Processus spinosus dorsalis. Aber ganz entsprechend dem Unterschiede in der Höhe der Localisation des krankhaften Processes constatirten wir eine ähnliche Differenz in der Lage der oberen Grenzen der in diesen Fällen beobachteten Thermoanalgesien. In beiden Fällen lag nämlich die obere Grenze der gekreuzten Thermoanalgesie ungefähr um 6 Dornfortsätze tiefer als der Sitz der Rückenmarksläsion. Es ist nicht erlaubt, aus diesen zwei Fällen irgendwelche allgemeinen Schlüsse zu ziehen. Man kann nur folgendes sagen: wenn dieses Verhältniss für alle Fälle zutreffen sollte, könnte man vielleicht aus der oberen Grenze der gekreuzten 
Thermoanalgesie einen genauen Schluss in Bezug auf die Localisation des krankhaften Processes ziehen: die Affection müsste auf der entgegengesetzten Seite liegen und zwar um ungefähr 6 Dornfortsätze über der oberen Grenze der Thermoanalgesie. Dabei könnten wir uns jedoch nicht nach der Zahl der Dornfortsätze, allein richten, weil auf verschiedener Höhe des Rückenmarks gleichen Abschnitten des Rückenmarks. nicht dieselbe Zahl der Dornfortsätze entspricht (infolge ihrer verschiedenen Inclination).

Andererseits aber werden wir uns gleich überzeugen können, dass. in Fällen von Compression des Rückenmarkes die obere Grenze der gekreuzten Thermoanalgesie nicht nur von der Höhe der Läsion des Rückenmarkes, sondern auch von ihrer Ausdehnung im queren Durchmesser abhängt. Es genügt, dass wir nur die Fig. 11 mit den Figuren 12 und 13 vergleichen. Wir sehen, dass bei einem und demselben Kranken mit der Meningomyelitis cervicalis superior e compressione die obere Grenze der gekreuzten Thermoanalgesie zu verschiedenen Zeiten verschieden hoch gelegen war: am 19. März 1903 (Fig. 11) stand die obere Grenze der gekreuzten Thermoanalgesie auf der Höhe des 1. Processus spinosus dorsalis und am 21. April 1903, d. b. 4 Wochen später, reichte sie nur noch bis zum 6. Dornfortsatz hinauf (Fig. 12 und 13). Die Lage der Affection des Rückenmarkes hat sich bei diesem Patienten während der Zeit nicht geändert. Das, was sich entschieden geändert hat, das ist die Tiefe der aus der Peripherie des Rückenmarkes sich gegen den Canalis centralis ausbreitenden Compression des Rückenmarkes. Das allmähliche Zurücktreten der krankhaften Erscheinungen bei unserem Patienten konnten wir ja nur durch eine allmähliche $\mathrm{Ab}$ nahme der Compression des rechten Seitenstranges des Rückenmarkes erklären: die Compression (infolge der Lymphstauung und des collateralen Oedems) des Seitenstranges wurde immer oberflächlicher, bis sie sich nur noch auf die rechte seitliche Peripherie des Rückenmarkes beschränkte. Das Sinken der oberen Grenze der gekreuzten Thermoanalgesie kann somit nur durch dieses Zurücktreten der Compression des Seitenstranges erklärt werden. Auf diesen Punkt werden wir weiter unten noch einmal zurückkehren.

Voriäufig will ich noch einen Fall von Erkrankung des Rückenmarkes, nämlich einen Fall von Myelitis transversa hier anführen, bei dem ich neben anderen Symptomen auch wiederum in der Gegend der oberen Grenze der bilateralen Thermoanästhesie dieselbe Dissociation der Schmerz-, der Wärme- und der Kälteempfindung beobachtet habe.

Fall III. Thomas Z., 61jähriger Bodenwischer (Frotteur), wurde am 13. Januar 1904 auf die Nerven-Abtheilung gebracht. Vor 7 Monaten, kurz 
unmittelbar nach einer acuten Erkrankung, bekam Z. neuralgische Schmerzen in der Regio interscapularis; diese Schmerzen waren sehr heftig und traten anfallsweise auf. In den Beinen traten Paraesthesien auf; auch waren die Füsse immer so kalt, dass er sie nie hat erwârmen können. Gieichzeitig stellte sich eine Schwäche beider Beine ein. Vor 3 Monaten hatte er unter einer sehr hartnäckigen Obstipation zu leiden, die jetzt verschwunden ist. Seit einigen Monaten bütete er das Bett, weil er sich nicht mehr auf den Beinen halten konnte. Bei der Untersuchung fand ich folgendes: Z. ist ein grossgewachsener, stark abgemagerter und geschwächter Mann, der weder gehen noch sich aufrecht halten noch sitzen kann. Mit den Beinen kann er auch nicht die geringste Bewegung ausführen: beide Beine sind vollständig gelähmt. In der Fegend der oberen Partio der Rürkenwirbelsänle constatiren wir einen geringen Buckel, der, nach Angabe des Patienten, sich erst in der letaten Zeit entwickelt hat. Der Dornfortsatz des 3. Dorsalwirbels stand viel deutlicher hervor als die der Nachbarwirbel; an Stelle des 4. Dornfortsatzes fanden wir im Gegentheil eine Einsenkung. Der auf die Wirbelsäule in der Gegend des 4. Dornfortsatzes ansgeübte Druck war für den Patienten schmerzhaft. Patient klagte über-starke thoracale Gürtelschmerzen und über schmerzhafte Muskellirämpfe in den Beinen, hauptsächlich in den Waden. Er hustete stark; in der Lunge fanden wir manifeste Symptome der Phthisis pulmonom fibrosa. Dio activen Bewegungen mit den unteren Extremitäten waren aufgehoben, mit Ausnahme einer geringen kaum wahrnehmbaren Bewegung mit den Zehen. Die Steifigkeit der Beine war nioht sebr bedeutend; sie manifestirte sich bauptsächlich bei der forcirten Extension der Beine, in den Kniegelenken. Von Zeit zu Zeit kam es in den Beinen zu ganz spontanen und plötzlich auftretenden unwillkürlichen Bewegungen: Die Beine wurden dabei in den Hüft- and Kniegelenken stark und rasch gebeugt (Epilppsia spinalis). Während dieser Spontanbewegungen verspürte der Patient heftige Sehmerzen in den contrahirten Muskeln. Die Patellar- und Achillessehnenreflexe waren sehr schwach ausgeprägt. Der Reflex von Babinski war nicht vorhanden. Es bestand Incontinentia urinae et retentio alvi. Die tactille Sensibilität der unteren Extremitäten und des Abdomens war dentlich abgeschwächt und stellenweise sogar ganz erloschen. Die Schmerz- und Temperaturempfindung war erloschen vorne bis zur VI. Rippe und hinten bis zum 4. Processus spinosus dorsalis. Ein sehr tiefer Nadelstich auf der vorderen Oberfläche des Oberschenkels z. B. rief nach Verlauf einiger Secunden eine plötzliche Beugung und Erhebung des Beines hervor, ohne dass der Patient dabei irgend einen Schmerz von dem Nadeistich verspürte. Gegen Ende Februar 1904 wurde am Kopf des Patienten ein Extensionsapparat angelegt. Das Bett wurde auch so gestellt, dass der Kopf viel höher lag als die Beine (das Extensionsgewicht betrug ca. 20 Pfund; dieser Apparat wurde jeden Tag während 6 Stunden applicirt). Gleich in den ersten 2 Tagen steigerten sich die neuralgischen Gürtelschmerzen im Thorax sehr; in den darauf folgenden Tagen aber liessen sie allmälig nach bis sie ganz verschwanden. Die unwillkürlichen, plötzlich auftretenden, heftigen Spontanbewegungen in den unteren Extremitäten nahroen in der orston Zeit so sehr zu, 
dass der Patient Nachts gar nicht schlafen konnte. Aber auch diese Bewegungen traten allmälig bedeutend zurück. Am 16. März 1904 fand ich bei des Untersuchung folgendes: Patient war im Stande, das linke Bein in die

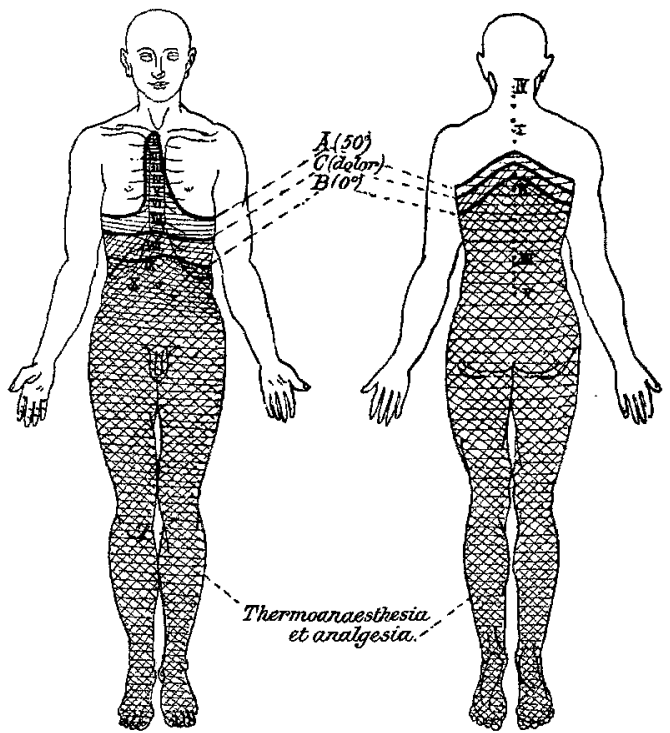

Fig. 14. Caries des dritten Dorsalwirbels. Paraparesis inferior. Hemithermoanalgesia bilateralis. Dissociation der Schmerz-, der Wärme- und der Kälteempfindung in der Gegend der oberen Grenze der Thermoanalgesie: A obere Grenze der Anästhesie für $+50^{\circ}, \mathrm{B}$ für $0^{\circ}$ und $\mathrm{C}$ für Schmerz.

Höhe zu heben; beugen konnte er es auch ganz gut, nur die Streckung war etwas erschwert. Das rechte Bein konnte Patient nur sehr wenig in die Höhe heben; die Beugung und Streckung im Kniegelenk waren müglich, aber gingen viel schwieriger von Statten als links. Die Dorsal- und Ventralflexion des Fusses führte Patient jedoch rechts besser aus als links. Unwillkürliche Spontanbewegungen kamen im linken Bein noch von Zeit zo Zeit vor; die Krämpfe im rechten Bein hatten fast vollständig nachgelassen. Der linke Patellarreflex war etwas gesteigert, der rechte normal. Ein schwacher Fussclonus bestand nur links. Incontinentia urinae blieb unverändert. Bei der Untersuchung der Sensibilität wurde bei überall gut erbaltener tactiler Sensibilität eine Thermoanalgesie der Beine und der unteren Partie des Abdomens festgestellt. Den Muskelsinn habe ich leider damals nicht untersucht. In der Gegend der oberen Grenze der erwähnten Thermoanalgesie fand ich wiederum dieselbe Dissociation der Schmerz-, der Wärme- und der Kälteempfindung, wie ich sie in den beiden citirten Fällen beobachtet habe. Wie wir aus der Fig. 14 ersehen können, liegt die obere Grenze der Anästhesie für $+50^{\circ}$ vorne auf der Höhe der VI. Rippe und hinten auf der Höhe des 3. Processus spinosus dorsalis; die obere Grenze der: Anästhesie für $0^{0}$ liegt vorne auf der Höhe der 
VII. und VIII. Rippe und hinten des 5. Dorsaldornfortsatzes; die obere Grenze der Analgesie $C$ liegt zwischen $A$ und $B$, und zwar vorne auf der Höhe der VI. und VII. Rippe und hinten des 4. Dorsaldornfortsatzes. Bei der Anwendung verschiedener Temperaturen überzeugte ich mich wiederum, dass die oberen Grenzen der Anästhesien für $+60^{\circ},+70^{\circ},+80^{\circ}$ etc. unterhalb der Linie A liegen und dass sie sich allmälig der Linie $C$ nähern and dass die oberen Grenzen der Anästhesien für $-5^{0},-10^{0}$ etc. oberhalb der Linie B liegen und sich allmählich der Linie $\mathrm{C}$ von unten her nähern.

Aus der Beschreibung der Krankheit ergiebt sich, dass wir es in diesem Fall mit Caries des dritten Dorsalwirbels zu thun hatten, in Folge deren eine Kyphose der Wirbelsäule mit Compression des Rückenmarkes entstanden ist. Es handelte sich um ein Mal de Pott mit Myelitis transversa mit Paraplegie und Störungen der Sensibilität der unteren Extremitäten und des Rumpfes. Die Application eines Extensionsapparates auf die Wirbelsäule verursachte eine Verminderung der Compression des Rückenmarkes; dem entsprechend sind auch viele krankhaften Störungen zurückgegangen. Mit dem Verschwinden der taktilen Sensibilitätsstörung sind auch die activen Bewegungen in den Beinen wieder zurückgekehrt. Dies beweist, dass der Druck auf die Goll'schen und Burdach'schen Stränge bedeutend, und auf die Pyramidenseitenstrangbahnen etwas abgenommen hat. Eine bilaterale Hemithermoanalgesie konnte man immer noch nachweisen.

Auf einen Unterschied in Bezug auf die Thermoanalgesie bei diesem Kranken und bei den vorher beschriebenen Fällen möchte ich hier hauptsächlich die Aufmerksamkeit lenken. In den beiden ersten Fällen lag die obere Grenze der gekreuzten Thermoanalgesie nicht unmittelbar unterhalb der Läsionsstelle des Rückenmarkes, sondern um etwa sechs Wirbel tiefer. In diesem dritten Fall dagegen beginnt die bilaterale Hemithermoanalgesie unmittelbar unter der Compressionsstelle des Rückenmarkes. Woher konmt das? Ich glaube, es kommt daher, dass neben einer Compression der Seitenstränge hier in Folge der Lymphstaung und des collateralen Oedems auch noch eine Compression der grauen Substanz vorhanden war, und dem entsprechend ausser einer bilateralen gekreuzten Hemithermoanalgesie noch eine bilaterale homologe Thermoanalgesie vorhanden war, die in Form einer Zone beiderseits die obere Grenze der bilateralen gekrenzten Hemithermoanalgesie überlagerte.

In allen drei Fällen jedoch beobachteten wir in der Gegend der oberen Grenze der Thermoanalgesie dieselbe Dissociation der Schmerz-, der Wärme- und der Kälteempfindung, die ich oben ganz ausführlich beschrieben habe. 
$\mathrm{Zu}$ den zwei ersten Fällen möchte ich noch folgendes bemerken: in dem Fall I, der traumatischen Verletzung des Rückenmarkes, liegt der Einstich rechts $1 \mathrm{~cm}$ von der Mittellinie entfernt. Dies spricht mit Gewissheit dafür, dass die rechte Hälfte des Rückenmarkes dabei verletzt wurde und zwar sehr wahrscheinlich nur ihre seitliche Peripherie. Die gefundene linksseitige Thermoanalgesie und die rechtsseitige Parese waren ein Beweis dafür. Bald aber, schon im Laufe der nächsten Woche, besserte sich die rechtsseitige Parese. Daraus musste der Schluss gezogen werden, dass die rechte Pyramidenseitenstrangbahn damals nicht durchgeschnitten worden war, sondern dass sie am Anfang nur unter dem Druck der Lymphstauung und des collateralen Oedems stand, welches in der unmittelbaren Nachbarschaft der Verletzungsstelle im Rückenmark zu Stande kam. Nach der Resorption der Lymphe und des Blutextravasates stellte sich die normale Function der rechten $\mathrm{Py}$ ramidenseitenstrangbahn wieder ein, der Patient konnte wieder gut laufen. Und da die Compression bei einer oberflächlichen Verletzung des Rückenmarkes zuerst im Centrum schwindet und sich am längsten in der Peripherie hält, sind wir gezwungen anzunehmen, dass die gebliebene linksseitige Thermoanalgesie von einer Compression derjenigen Bahnen des rechten Seitenstranges abhängig ist, die zwischen der Pyramidenseitenstrangbahn und der seitlichen Peripherie des Rückenmarkes liegen. Und da diese linksseitige Thermoanalgesie auch noch nach einem Jahre sich ganz und gar unverändert bei dem Patienten nachweisen liess, müssen wir annehmen, dass sie die Folge einer schweren und dauernden Verletzung dieser Bahnen ist. Da die Thermoanalgesie bei unserem Patienten als die einzige und isolirte krankhafte Erscheinung zurück geblieben ist, müssen wir annehmen, dass die die Temperatur- und Schmerzeindrücke leitenden Babnen ganz nahe der seitlichen Oberfläche des Rückenmarkes verlaufen, denn wenn diese Bahnen in der Tiefe gelegen wären, könnten sie nicht isolirt von aussen her verletzt werden. Welcher Art ist nun die Verletzung dieser im Seitenstrange, an der Oberfläche des Rückenmarkes liegenden, zur Leitung der Temperatur- und Schmerzempfindung bestimmten Bahnen in unserem Falle gewesen? Da die Thermoanalgesie sich bei unserem Patienten noch nach einem Jahre ganz unverändert constatiren liess, nehmen wir an, dass diese Bahnen durchschnitten wurden.

Zu dem zweiten Fall möchte ich noch folgendes hinzufügen: wie wir oben gesehen haben, war im Verlaufe der allmälig fortschreitenden Besserung bei Wilczynski ein Moment aufgetreten, in welchem er nur noch die Symptome einer rechtsseitigen Brown-Séquard'schen Lähmung zeigte. Es bestand nämlich damals bei ihm eine rechtsseitige 
Hemiparese und eine linksseitige Hemithermoanalgesie. Das deutete hin auf eine Affection der rechten Rückenmarkshälfte. Da aber nach einer gewissen Zeit sich die rechtsseitige Hemiparese fast vollständig zurückgebildet hat und nur noch die Thermoanalgesie geblieben ist, müssen wir annehmen, dass die rechte Pyramidenseitenstrangbahn wieder frei geworden ist, d. h. dass die durch Lymphstauung und collaterales Oedem bedingte Compression dieser Bahn zurückgegangen ist. Es blieb nun die Frage offen: durch Compression welcher Bahnen der rechten Rückenmarkshälfte ist die linksseitige Hemithermoanalgesie bedingt? Um diese Frage beantworten zu können, dürfen wir vor allem nicht vergessen, dass in diesem Falle die Ursache der Rückenmarkscompression von einer pathologischen Veränderung der knöchernen Wand des Canalis vertebralis ausging. In solchem Fall muss der mechanische Druck, die dadurch bedingte Lymphstauung und das collaterale Oedem am stärksten in denjenigen Theilen des Rückenmarkes ausgeprägt sein, welche dem krankhaften Process am nächsten sind, und am schwächsten in denjenigen Theilen, welche von dem krankhaften Process am weitesten enfernt sind. Am nächsten dem krankhaften Processe liegt in unserem Fall die Peripherie des Rückenmarkes und am weitesten von ihm entfernt ist das Innere des Rückenmarkes. Aus dem Verlauf der Krankheit bei W. sahen wir, dass am Anfang das ganze Rückenmark comprimirt und später nur noch seine rechte Hälfte afficirt war. Schliesslich hat sich sogar das Symptom einer Compression der rechten Pyramidenseitenstrangbahn fast ganz zurückgebildet und als einzige krankhafte Störung blieb noch die linksseitige Thermoanalgesie. Durch Compression welcher Bahnen der rechten Rückenmarkshälfte war diese linksseitige Thermo. analgesie bedingt? Meiner Meinung nach war sie bedingt durch eine noch bestehende Compression derjenigen Bahnen des rechten Seitenstranges, welche zwischen der Pyramidenseitenstrangbahn und der Peripherie des Rückenmarkes gelegen sind. Denn wenn die Ursache der Rückenmarkscompression von der Peripherie ausgeht, ist die Compression der Peripherie des Rückenmarkes am stärksten und die des Inneren des Rückenmarkes am schwächsten, und bei dem Zurückgehen einer solchen Compression muss dieselbe zuerst das Innere des Rückenmarkes verlassen und am längsten an der Peripherie verbleiben. Da in unserem Falle die Pyramidenseitenstrangbahn allmälig fast ganz von der Compression befreit wurde, sind wir gezwungen die linksseitige Thermoanalgesie durch eine Compression derjenigen Bahnen zu erklären, die zwischen der rechten Pyramidenseitenstrangbahn und der Peripherie des Rückenmarkes liegen.

Wir sehen nun, dass beide Fälle uns dazu zwingen, anzunehmen, 
dass die zur Leitung der Temperatur- und Schmerzempfindung bestimmter Bahnen im contralateralen Seitenstrange verlaufen, und zwar in dessen seitlicher Peripherie.

Wenn dies richtig wäre, müssten wir bei den mikroskopischen Untersuchungen des Rückenmarkes in Fällen von completer traumatischer Querläsion des Rückenmarkes oder bei Myelitis transversa in dem oberen Abschnitt des Rückenmarkes in der seitlichen Peripherie des Rïckenmarkes jedesmal deutliche aufsteigende Degeneration antreffen. Was finden wir bei solchen Untersuchungen? Wir finden in der Regel eine aufsteigende Degeneration der Hinterstränge, der Kleinhirnseitenstrangbahn and des Gowers'schen Bündels. In einem von diesen Gebieten muss nun die zur Leitung der Temperatur- und Schmerzempfindung bestimmte Bahn liegen. Wir wissen aber, dass die Hinterstränge taktile Sensibilität leiten und dass sie aus ungekreuzten Bahnen zusammengesetzt sind; aus demselben Grunde kann auch die Kleinhirnseitenstrangbahn ausgeschlossen werden, weil sie auch aus ungekreuzten Fasern besteht; die zur Leitung der Temperatur- und Schmerzempfindung bestimmte Bahn ist aber eine gekreuzte Bahn. Es bleibt also nur das Gowers'sche Bündel oder der Tractus. Fasciculus antero-lateralis ascendens, der die zur Leitung der Temperatur- und Schmerzempfindung dienende Bahn enthalten kann. Und diese Ansicht wird auch von den meisten Forsehem vertreten: Raymond, Edinger, Schlesinger, Lähr, von Reusz, Henneberg, Bechterew und Holzinger nehmen an, dass die zur Leitung der Temperatur- und Schmerzempfindung dienende Bahn im contralateralen Seitenstrange hirnwärts zieht. Van Gehuchteu, Brissaud, Llyod, Grasset, Petrén Kohnstamm und Mai sind der Ansicht, dass sie in dem contralateralen Gowers'schen Bündel hirnwärts geleitet wird. Gegen diese letzte Auffassung haben sich, wie wir oben gesehen haben, nur Herzen, Dejerine, Thomas und Hoche ausgesprochen. Herzen kam zu einer anderen Ansicht auf Grund eines Falles von Pachymeningitis hypertrophica, den aber Goldscheider und Mai auch auf andere Weise zu erklären versuchen. Viel gewichtiger sind die Herzen'schen Thierexperimente, auf Grund deren er zu der Ueberzeugung gelangt, dass. die Bahnen zur Leitung der Kälteempfindungen nur in der gleichnamigen Hälfte des Rückenmarkes, nämlich in den Hintersträngen, enthalten sind und die Schmerzempfiudung auf beiden Seiten des Rïckenmarkes, und zwar in der grauen Substanz hirnwärts geleitet wird. Andererseits haben wir oben gesehen, dass Bechterew und Holzinger auf Grund ihrer Experimente zu der Ueberzeugung kamen, dass die Schmerzempfindungen in den Seitensträngen hirnwärts ziehen. Die Widersprüche 
beweisen, dass wir noch weitere diesbezügliche Untersuchungen abwarten müssen, bis wir die Resultate der experimentellen physiologischen Forsehung zur Lösung djeser Fragen beim Menschen werden verwenden können. Dejerine macht darauf aufmerksam, dass es Fälle gibt mit Degeneration des Gowers'schen Bündels, die keine Sensibilitätsstörungen aufweisen. Wenn die Ansicht ron Edinger, Kohnstamm, u. a. richtig ist, dass das Gowers'sche Bündel aus verschiedenen Fasern, nämlich aus solchen, die zum Kleinhirn geben und solchen, die bis zum Thalamas opticus und medialen Schleife verfolgt werden können, wäre es erklärlich, warum eine partielle Degeneration des Gowers'schen Bündels, nämlich der zum Cerebelum ziehenden Bahnen, keine Sensibilitätsstörung aufweist. Die Ausicht Hoche's, dass die Fasern des Gowe:s'schen Bündels fast ausschliesslich zum Kleinbirn ziehen, wurde ja von anderen Forschern widerlegt.

Jetzt möchte ich noch einmal auf die Thatsache hinweisen, dass in meinem Fall I die obere Grenze der gekreuzten Thermoanalgesie am ca. 6-7 Dorufortsätze tiefer lag, als der Sitz der contralateralen Rückenmarksverletzung. Dass dies nicht nur ein Zufall ist, sondern dass vielmehr zwischen dem Sitz der Halbseitenverletzung des Rückenmarkes und der oberen Grenze der gekreuzten Thermoanalgesie ein constantes Verhältniss bestehen muss, berieist der Umstand, dass andere Autoren auch ähnlicheş beobạchtet haben: ich führte schon oben an, dass in den Fällen von Halbseitenläsion des Rückenwarkes, wejche von Lähr, v. Reinhard, Crocqu. a. beschrieben haben, die obere Grenze der gekreuzten Thermoanalgesie auch nm 6-7 Wirbel tiefer lag, als die Hemiläsion des Rückenmarkes. Diese Erscheinnng können wir unș uur so erkläret, indem wir annehmen, dass der Uebergang der die Temperatur- und Schmerzempfindung leitenden Bahn sich vom Hinterhorn der einen Seite bis zum Seitenstrange resp. zum Gowers'schen Bündel der anderen Seite ganz allmählich vollzieht und zwar, dass diese Bahn von der hinteren Wurzel aus durch das Hinterhorn bis zur Nedianebene allmähJich auf einer Höbe ron ca. 3 Wirbeln geschieht und weiter, dass der Uebergang von der Medianebene durch die graue Substanz und durch den Seitenstrang bis zur Peripherie des Rückenmarkes resp. zum Gowers'schen Bündel auch allmäblich ungefähr erst auf einer Höhe von 3 Wirbeln stattfindet. Ind dies würde uns auch erklären, warum bei verschiedenen einseitigen Rückenmarksverletzungen das Verbültniss zwischen der oberen Grenze der gekreuzten Thermoanalgesie und dem Sitz der Rückenmarksläsion nicht immer dasselbe bleibt, worauf, wemn jch mich nicht irre, schon Raymond aufmerksam semacht hat. Es ist ja leicht verstindlich, dass, wemn z. B. die uns - archir f. Psychiatrie. H\&l. 41. Heft 3. 
interessierende Bahn an einer zwischen der Medianebene und der Peripherie des Seitenstranges resp. des Gowers'schen Bündels unterbrochen wird, dann muss die obere Grenze der contralateralen Thermoanalgesie wenigstens um 3 bis 6 Wirbel unterhalb der Läsionsstellc liegen. Dass diese Auffassung richtig ist, beweisen die diesbezüglichen Literaturangaben: so $\operatorname{lag}$ z. B. die obere Grenze der gekreuzten Thermoanästhesie in einem Fall von Halbseitenläsion des Rückenmarks, den v. Reusz beschreibt, nur 3 Wirbel unterhalb der Läsionsstelle, in dem Fall von halbseitiger Apoplexie in die Medulla oblongata - ungefähr ım 4 Segmente tiefer als die vermuthliche Läsion, in dem Fall von Gumma medullare von Hanot und Meunier - um 3 Wirbel tiefer. Die verschieden hohe Lage der oberen Grenze der gekreuzten Thermoanalgesie hängt nur von der Tiefe (in querer Richtung) der Rückenmarksläsion ab. Wir besitzen jedoch einige Anhaltspunkte, um die Tiefe der Halbseitenläsion in gegebenem Falle einigermaassen zu bestimmen: bei einer vollständigen Halbseitenläsion des Rückenmarkes, die exact bis zur Medianebene geht, beobachten wir in der Regel neben der gekreuzten Hemithermoanalgesie noch eine gleichseitige Hemiparese, Fehlen des Muskelsinnes auf der gleichen Seite und atrophische Störungen in denjenigen Muskeln, deren trophische Centren gerade in dem verletzten Vorderhorn gelegen sind, eine ungekreuzte Zone von Sensibilitätsstörungen im Niveau der Läsion selbst $u$. s. f. mit einem Worte, wir beobachten in solchen Fällen das complete Syndrom, wie es BrownSéquard bei einer Halbseitenläsion beschrieben hat. Eine Halbseitenläsion des Rückenmarkes aber, die z. B. nur die Peripberie des Seitenstranges und die Pyramidenseitenstrangbahn lädirt hat, ist nicht mehr von einem vollständigen Brown-Séquard'schen Symptomencomplex begleitet, da in einem solchen Fall nur eine gekreuzte Thermoanästhesie, eine gleichseitige Hemiparese und event. ein Fehlen des Muskelsinnes auf der Seite der Läsion beobachtet wird. Und schliesslich eine Halbseitenläsion des Rückenmarkes, die nur die Peripherie des Seitenstranges zerstört hat, die Pyramidenseitenstrangbabn dagegen frei. lässt, giebt uns nicht einmal einen uncompleten Brown-Séquard'schen Symptomencomplex, sondern ganz einfach nur eine einfache, oft isolirt auftretende gekreuzte Thermoanalgesie.

Der Fall I ist ein Typus derartiger Halbseitenverletzung des Rückenmarkes: die gekreuzte Thermoanalgesie war das einzige Symptom, das zurückgeblieben ist. Am Anfang, gleich nach der Verletzung, beobachten wir in solchen Fällen in der Regel ein uncompletes BrownSéquard Syndrom, welches durch. eine gleichzeitige Compression der Pyramidenseitenstrangbahn in Folge der Lymphstaung and des colla- 
Zum Studium der Dissociation der Temperatur- u. Schmerzempfindung. 997

teralen Oedems entstanden ist. Aus dem Gesagten können wir also folgende Schlüsse ziehen: bei einer vollständigen Halbseitenläsion des Rückenmarkes liegt die obere Grenze der gekrenzten Thermoanalgesie nur um drei Wirbel tiefer als die Läsionsstelle; diejenigen Fälle, in welchen die Verletzung die Peripherie des Seitenstranges und die Pyramidenseitenstrangbahn zerstört bat, die graue Substanz aber intakt gelassen hat, liegt die obere Grenze der gekreuzten Thermoanalgesie ungefähr um 4-5 Wirbel tiefer als die Läsionsstelle. Und nur bei Verletzung der Peripherie des Rückenmarkes ohne Läsion der Pyramidenseitenstrangbahn, liegt sie um sechs Wirbel tiefer als die Läsionsstelle.

Wenn die Rückenmarkstäsion die zur Leitung der Schmerz- und T'emperaturempfindung bestimmte Bahn auf dem Wege zwischen dem Eintritt derselben in das Rückeumark und der Medianebene trifft, damn haben wir in der Regel eine gleichseitige Thermoanalgesie, deren obere Grenze entweder gleich unterhalb der Läsionsstelle oder höchstens bis drei Wirbel unterhalb der Läsionsstelle liegt.

Zur Erläuterung der Abhängigkeit verschiedener Sensibilitätsstörungen vou der Localisation des krankhaften Processes in der grauen Substanz, sei es mir erlaubt, zwei schematische Zeichnungen hier einzufügen. Diese Zeichnungen sollen jedoch nur den einzigen Zweck haben, uns weitläufige Beschreibungen des Verlaufes dieser Bahnen im Grau des Rückenmarkes zu ersparen. Die Fig. 15 zeigt uns, wie ein Theil

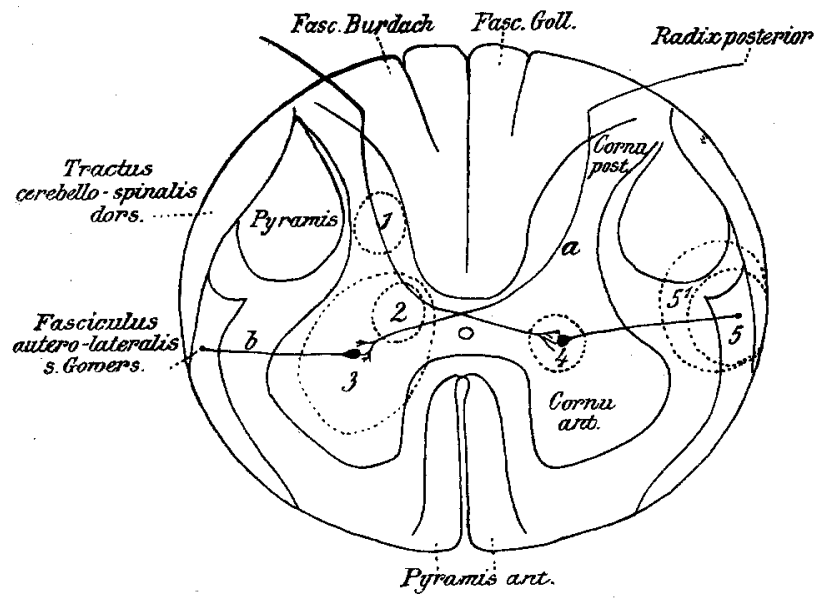

Fig. 15. Schema eines Querschnittes des Rückenmarkes zur schematischen Darstellung des Verlautes der zur Leitung der Temperatur- und Schmerzemfindung bestimmter Bahn: a erstes Neuron, b zweites Neuron dieser Bahn, 1, 2, 3 und 4 Herde in der grauen Substanz des Rückenmarkes, 5, 51 Herde im Seitenstrange. 
der hinteren Wurzel das Hinterhorn erreicht, in der grauen Substanz weiterzieht, die Medianlinie kreazt und sich im contralateralen Vorderhorn einem anderen Neuron anschliesst, dessen Fortsetzung nun bis in. die seitliche Peripherie des Seitenstranges (resp. in das Gowers'sche Bündel) zieht; die Bahn a soll in schematischer Weise den Verlauf der die Temperatur. und Schmerzempfindung leitenden Bahn wiedergeben. Die Fig. 16 soll die almälige Steigerung dieser Babn in verticaler

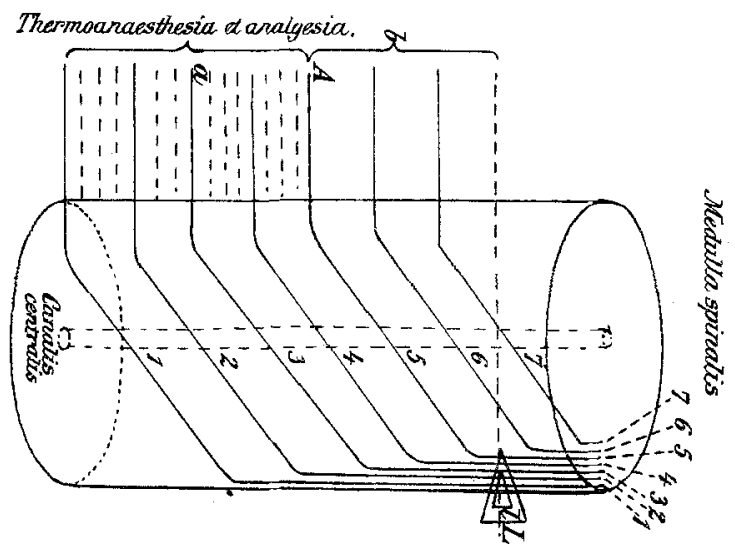

Fig. 16. Schematische Darsteling des Verlaufes im Rückenmarke der zur Leitung der 'Temperatur- und Schmerzempfindung dienenden Bahn. 1, 2, 3, 4, 5, 6 und 7 Längsfasern dieser Bahn; L tiefe Verletzungen der Peripherie des. Seitenstranges; 1 ganz oberflächliche Vorletzung des Seitenstranges. A obere(Trrenze der Therravanalgesie bei Läsion L, a bei Läsion I; b Distanz, die sechs. Wirbeln entspricht.

Richtung angeben. Eine im Hinterhorn localisirte Läsion 1 wird eine gleichseitige Thermoanalgesie in Form einer schmalen Zone, resp. eines. halben Gürtels, dessen obere Grenze unmittelhar unter der Läsionsstelleliegt, zar Folge haben. Bei einer Läsion 2, die in dem centralen Grau, zwischen dem Hinter- und Vorderhorn, liegt, beobachten wir in der Regel eine bilaterale beschränkte Thermoanalgesie in Form zweier Halbzonen, wobei jedoch die obere Grenze der gleichseitigen Zone unmitte]bar unterhalb der Lüsionsstelle liegt, dagegen die obere Grenze der gekreuzten Thermo-Anästhesie und -Analgesie ungefähr vier Wirbel: tiefer liegt als der Sitz der Läsion im Rückenmarke. Und wenn die Iäsion eine so grosse Ausdehnung erreicht, dass sie auch das Vorderhorn in Mitleidenschaft zieht, dann beobachten wir gewöhnlich noch eine Atrophie der entsprechenden Muskeln auf der Seite der Läsion (Läsion 3). Bei einer Läsion 4 (Fig. 15) haben wir gewöhnlich neben der Atrophie der entsprechenden Muskeln derselten Seite auch eine 
gekreuzte Thermoanalgesie in Form einer Hemizone, deren obere Grenze ungefähr vier Wirbel tiefer liegt als die Läsionsstelle. Wie wir sehen, giebt eine Läsion der grauen Substanz, ganz unabhängig von ibrer Lacalisation in der Regel nur eine beschränkte Thermoanalgesie in Form einer Hemizone und nur in dem diesem Rückenmarksegment entsprechénden Hautbezirke. Ganz andere Störung der Temperatur- und Schmerzempfindung dagegen beobachten wir daun, wenn die Läsion in der Peripherie der Seitenstränge localisirt ist (Läsion ち). Die Störung ist dann immer eine gekreuzte und eine complete, d. h., dass sie an den Zehen beginnt und bis za einer.gewissen Höhe reicht; wir haben dann immer eine Hemithermoanalgesie. Und wenn eine solche Läsion sehr weit ausgedehnt ist, so dass sie auf den Pyramidenseitenstrang sowohl wie auch auf die grane Substanz übergreift, dann haben wir gewöhnlich vor uns den Brown-Séquard'sehe Symptomencomplex, d. h. eine gleichseitige Hemiplegie mit einer gekrenzten Thermoanalgesie, deren obere Grenze ungefähr vier Wirbel tiefer liegt als die Läsionsstelle und eine gleichseitige Thermoanalgesie in Form einer Hemizone auf der Höhe der Läsionsstelle etc. Eine Läsion der seitlichen Peripherie des Seitenstranges mit gleichzeitiger Läsion (z. B. einer Compression) der Pyramidenseitenstrangbahn (Läsion $5^{1}$ ) ruft nur ein modificirtes, unvollständiges Brown-Séquard'sches Syndrom hervor, d. b. nur eine gleichseitige Hemiplegie mit einer gekrenzten. Hemithermoanalgesie, deren obere Grenze um sechs Wirbel tiefer liegt als die Läsionsstelle selbst. Schliesslich giebt es ganz unbedeutende, umschriebene Läsionen (Lüsion 5) der seitlichen Peripherie des Seitenstranges, resp. des Gowers'schen Bündels, welche nur eine gekreuzte Hemithermoanalgesie nach sich ziehen, deren obere Grenze sechs Wirbel tiefer liegt als der Sitz der Läsion. Solche in der grauen Substanz localisirte Herde bietet uns oft die Syringomyelie, wo auch die verschiedenen oben erwähnten Arten der Sensibilitätsstörungen beobachtet werden. Hemiplegie mit gekreuzter Hemithermoanalgesie sehen wir meistens bei tieferen traumatischen Halbseitenläsionen des Rückenmarkes, welche sich jedoch nur auf die weisse Substanz beschränken und isolirte gekreuzte Hemithermoanalgesie beobachteten wir nur bei ganz oberflächlichen traumatischen Stichverletzungen der seitlichen Peripherie des Rückenmarkes, resp. des Gowers'schen Bündels, wie das bei Z. z. B. der Fall war.

Auf Grund der klinischen Erfahrung und auf Grund pathologischanatomischer Erwägungen sind wir oben zu der Ueberzeugung gekommen, dass die zur Leitung der Temperatur- und Schmerzempfindung dienende Bahn im contralateralen Gowers'schen Bündel verläuft. Das Gower's- 
sche Bündel liegt in der seitlichen Peripherie des Rückenmarkes, aber, wie wir aus der Fig. 15 seben, im seitlichen-vorderen Quadranten des Rückenmarksquersehnittes. Daraus folgt, dass ein Stich, der vom Rücken herkommt und das Gowers'sche Bündel erreichen solI, nothwendigerweise vorher die (gleichseitige) Kleinhirnseitenstraugbahn lädiren muss. Solche Läsion nehme ich in meinem Fall 1 auch an.

Noch auf einen besonderen Umstand in der Krankengeschichte meines zweiten Falles von Myelitis cervicalis e compressione möchte ich die Aufmerksamkeit lenken nämlich darauf, dass mit der Abnahme der Compression des Rückenmarkes, d. h. mit dem Schwinden der Lymphstauung und des collateralen Oedems aus dem Inneren des Rückenmarkes gleichzeitig auch die obere Grenze der gekreuzten Henithermoanalgesie allmälig zu sinken anfing: am 19. März 1903 reichte dieselbe bis zur Höhe des ersten Dorsaldornfortsatzes. Diese Thatsache könuen wir uns leicht erklären, wenn wir annehmen, dass in dem Gowersschen Bündel selbst die vom Bein kommenden Bahnen am meisten peripheriewärts, die vom Rumpf kommenden mehr einwärts und die von der Oberextremität kommenden Bahnen am meisten einwärts im Rückenmarke liegen, so dass z: B. die beiden ersten und ein Theil del zweiten noch unter dem Einfluss eines von der Peripherie ausgehenden: Druckes stehen können, währenddem die am meisten nach innen gelegenen Bahnen in Folge der Resorption der Lymphe, des Oedems und des Blutextravasates im Inneren des Rückenmarkes schon vom Drucke befreit sein können. Dies soll uns die Fig. 16 bildlich darstellen: bei einer in die Tiefe des Rückenmarkes eingreifenden Läsion L liegt die obere Grenze A der gekreuzten Thermoanalgesie um 6 Wirbel tiefer als die Läsionsstelle selbst, dagegen bei einer nur in die Peripherie des Rückenmarkes eindringenden Läsion $l$, die nar die an der Oberfläche verlaufenden Nervenbahnen 1,2 und 3 unterbricht, wird sie nur bis zur Linie a binaufreichen können.

In Bezug auf die eigenartige in diesen Fällen beobachtete Dissociation der Temperatur- und Schmerzempfindung möchte ich noch folgendes bemerken: der Umstand, dass bei ganz oberflächlicher Seitenverletzung des Rückenmarkes - wenn dies immer der Fall sein sollte? die oberen Grenzen der Anästhesien anf $0^{0},+50^{\circ}$ und auf Schmerzreize so nahe bei einander liegen und dass die oberen Grenzen der Anästhesie für Temperaturen über $+50^{\circ}$ und unter $0^{\circ}$ schliesslich mit der oberen Analgesiegrenze rerschmelzen, scheint dafür zu sprechen, dass diese drei Empfindungsqualitäten in enger Beziehung zu einander stehen und die Leitungen derselben im Rückenmark sehr nahe bei einander liegen müssen. 
Zum Studium der Dissociation der Temperatur- u. Schmerzempfindung. 1001

Auf Grund der aus der Literatur zusammengestellten Thatsachen, auf Grund meiner persönlichen Beobachtungen und auf Grund aller in dieser Arbeit geäusserten Erwägungen bin ich zu folgenden Schlüssen gekommen:

\section{Zusammenfassung.}

1. Störungen der Temperatur- und Schmerzempfindung können cerebralen, spinalen und peripherischen Ursprungs sein, wir beobachten sie bei Hysterie, bei capsulären und corticalen Hemiplegien; bei Compression, Verletzung oder Erkrankung der peripherischen Nerven und bei Verletzungen und Erkrankungen des Rückenmarkes.

2. Spinale Thermoanalgesie kommt vor bei Syringomyelie, bei traumatischen Verletzungen des Rückenmarkes, bei Compression des Rückenmarkes, bei Haematomyelia centralis sowobl wie auch bei Apoplexie in den Seitenstrang, bei Tabes, Pachymeningitis hypertrophica, Syphilis spinalis, Myelitis e compressione und bei chronischer Myelitis.

3. Die Topographie der spinalen Thermoanästhesie resp. ihre Verbreitung auf der Hautoberfläche ist eine radiculare.

4. Im Rückenmarke existirt eine besondere Bahn zur Leitung der Temperatur- und Schmerzeindrücke, welche von den Bahnen, die zur Leitung der tactilen Sensibilität und des Muskelsinues dienen, anatomisch getrennt ist.

5. Die Localisation oder der Verlauf dieser zur Leitung der Temperatur- und Schmerzeindrücke bestimmten Bahn ist folgender: hintere Wurzel, Hinterhorn, vordere Commissur der grauen Substanz, Vorderseitenstrang und seitliche Pe. ripherie desselben, aller Wahrscheinlichkeit nach das Gowers'sche Bündel.

6. Die zur Leitung der Temperatur- und Schmerzempfindung dienende Bahn besteht aus 2 Neuronen: die Nervenzelle des ersten Neurons') liegt in dem Spinalganglion, die Zelle des $z$ weiten ${ }^{2}$ ) in der grauen Substanz der contralateralen Hälfte des Rückenmarkes.

7. Eine unilaterale Läsion der grauen Substanz des Rückenmarkes giebt a) eine gleichseitige (homologe) Thermoanalgesie, wenn sie sich auf das Hinterhorn beschränkt

1) des Protoneurons nach Brissaud.

2) des Deuténeurons n. B. 
(dort wo das Protoneuron durchzieht), b) eine gekreuzte Thermoanalgesie, wenn sie die graue Substanz in der Nähe des Vorderhorns zerstört, gerade dort, wo die von der entgegengesetzten Seite kommenden Deuteroneuronen durchgehen und c) eine bilaterale Thermoanalgesie.

8. Eine beschränkte Läsion der grauell Substanz giebt immer eine Thermoangesie, die sich auf eine bestimmte Hautoberfläche beschränktin Form einer Hemizone, welche immer den entsprechenden lädirten Medullarsegmenten genau entspricht.

9. Eine Läsion des Seitenstranges mit Einschluss der seitlichen Peripherie desselben resp. des Gowers'schen Bündels hat immer eine totale gekreuzte Thermoanalgesie, die von deu Zehen hinaufsteigt, zur Folge.

10. Die Hemizone der gleichseitigen Thermoanalgesie. welche durch eine Läsion der grauen Substanz (resp. des Hinterhorns) hervorgerufen ist, beginnt in der Regel unmittelbar unter der Läsionsstelle und die der contralateralen, die durch eine Läsion der grauen Substanz, in der Nahe des Vorderhorns, hervorgerufen ist, beginnt ungefähr 4 Wirhel unterhalb der Läsionsstelle.

11. Die oboro frenze der tutalen gekreuzten Thermoanalgesie, die durch eine Läsion der weissen Substanz, resp. des Seitenstranges mit Einschluss des Gowers'schen Bündels bedingt ist, liegt ungefähr fünf Wirbel tiefer unterbalb der Läsionsstelle;

12. Die obere Grenze der totalen gekreuzten Thermoanalgesie, die durch eine Läsion der seitlichen Peripherie des Seiteustranges, resp. des Gowers'schen Bündels bedingt ist, liegt ungefähr sechs Wirbel unterbalb der Läsionsstelle;

13. In der Gegend der oberen Grenze der gekreuzten totalen Thermoanalgesie finden wir oft eine Dissociation der Wärme-, der Kälte- und der Schmerzempfindung, wobei die obere Grenze der Wärmeanästhesie am höchsten, die der Kälteanüsthesie am tiefsten und die der Analgesie zwisehen beiden liegt;

14. Die Dissociation der Wärme und der Kälteempfindung erreicht ibr Maximum bei der Anwendung von $+50^{\circ}$ und $0^{\circ}$;

15. Die oberen Grenzen der Thermoanasthesien für Temperatur äber $+50^{\circ}$, d. h. für $+60^{\circ}$, $+70^{\circ},+80^{\circ}$ u. s. f., liegen 
Zum Studium der Dissociation der Temperatur- u. Schmerzempfindung, 1003

allmälig immer tiefer unter der oberen Grenze der Thermoanästbesie für $+50^{\circ}$ und nähern sich der oberen Grenze der Analgesie von oben her;

16. Die oberen Grenzen der Thermoanasthesien fûr Tem. peraturen unter $0^{0}$, nämlich für $-\dot{j}^{9},-10^{\circ}$ etc., liegen allmälig böher als die obere Grenze der Thermoảuästhesie für $0^{3}$ und nähern sich allmälig der oberen Grenzeder Analgesie von unten her.

17. Die oberen Grenzen der Thermoanäschesien für Temperatur zwischen $0^{\circ}$ und $+50^{\circ}$ liegen $z$ wischen den oberen Grenzen für diese beiden Temperaturen.

Krakau, den 12. September 1905.

\section{Literatur.}

Alter, W., Perverse Temperaturempfindung. Neurolog. Centralblatt, 1903, No. 16.

Balint, R, Ein Fall von Hirnstammerkrankung mit dissociirter Sensibilitätslähmung. 1903. Ref. im Neurolog. Centralblatt, 1904, p. 917.

r. Bechterew und Holzinger, Die sensiblen Bahnen im Rückenmark. Neurolog. Centralblatt, 1894.

Böttiger, Ein operìrter Rückenmarkstumor. Areh. f. Psychiatrie Bd. 35, H. 1. 1902.

Bottarzi, Ueber die Hemisection des Rückenmarkes bei Hunden. Centralblatt f. Physiologie, VII, p. 531. 1895.

Breg mann, Hämatomyelia centralis. Kronilia lekarska, 1897, No. 9 unả 10 (polnisch). Deutsch. Zeitschr. f. Nervenh. Bd. X, p. 478.

Brissaud, E., Le double syndrôme de Brown-Séquard dans la syphilis spinale. Le Progrès Méd., 17. Juil. 1897, p. 36.

Brown-Séquard, Recherches sur la transmission des impressions de tact, de chatouillement, de douleur, de temperature et de contraction (sens muscnlaire) dans la moëlle épinière. Journ. de la physiol. eto., VI, 1863, No. 14 et 15, p. 124.

Bruns, Klinische und pathologische Beiträge zur Chirurgie der Rückenwarkstumoren. Arch. f. Psych., XXVIII, 3, 1896.

Charcot, J. B., Sur un cas de dissociation de la sensibilité à type syringomyélique consécutive à une compression. Comptes-rendus.

Charcot et Gombault, Archives de Physiologie. 1873, vol. V, p. 143.

Chatin, P., Dê la sensibilité thermique dissociée chez les hómiplégiques. Arch. gén. de méd, Janvier 1900, p. 66.

Ciaglinski, Lange seusible Bahnen in der grauen Substanz des Rürskenmarkes und ihre experimentelle Degeneration. Neurolog. Centralblatt, 1896, S. 773 . 
Crocq, Un cas de Brown-Séquard avec dissociation syringomyélique de la sensibilité. Comptes-rendus de la séance du 26 novembre 1898 de la Soc. belge de Neurologie. Journ. de Neurologie, 1899, No. 3, p. 56.

Dejerine et Thomas, Un cas d'hémiparaplégie avec anesthésie croisée. Syndrôme de Brown-Séquard suivi d'autopsie. Archives de physiol., 1898, No. 3, p. 594.

Dejerine, Progès Médical, 1898, No. 6, p. 87.

Dejerine, Sémiologie du système nerveux. Traité de pathologie générale publié par Ch. Bouchard etc., 1901, p. 879.

Dejerine et Thomas, Traité des maladies de la moëlle épinière, Paris, 1902, p. 217.

Dydynski, Ueber den Verlauf einiger Rückenmarksbahnen. Vortrag gehalten in der Warsohauer Aerztegesellschaft am 26. November 1901, Neurolog. Centralblatt, 1903, S. 502.

Edsall, D. L., Dissociation of sensation of the syringomyelie type occuring in Pott's disease. Journ. of Nervous and Ment. Disease, 1898.

Edinger, Vorlesungen über den Bau der nervösen Centralorgane. 4. Auflage, S. 161, 1894.

Ferrari, G., Alterazioni della sensibilità tattile e termica in seguito a lesione di un ramo digitale del nerro mediano. Riv. speriment. di freniatria, 1900. Jahresbericht der Neurol. und Psych. 1900, S. 145.

v. Frey, Max. Beiträge zur Sinnesphysiologie. Bericht der mathem.-phys. Klasse der Gesellschaft der Wissenschaften. Leipzig. 1895.

Fla tau, Ed, und Koelichen, Demonstration eines Mediastinaltumors in der Warschauer Aerztegesellschaft am 3. XI. 1903. Pamietnik Towarzystwa Lekarskiego Warszawskiego, 1903, p. 1006.

Fürnrohr, Ein Fall von Brown-Séquard'scher Halbseitenlähmung nach Stichverletzung des Rückenmarks. Dent. Zeitschr. für Nervenh., XXII, 1902; Ref. im Neurolog. Centralblatt, 1903, S. 78.

Goldscheider, A., Zur Dualität des Temperatursinnes. Pfläger's Arch. f. Physiol., 1886, Bd. 39.

Gowers, Handbuch der Nervenkrankheiten. Bonn, 1892.

Van Gehuchten, Anatomie du système nervenx de l'homme. Lierre, 1893, p. 654 .

Van Gehuchten, Anatomie du système nerveux de l'homme. Louvain, 1895, p. 880.

Van Gehuchten, Le mécanisme des mouvements réflexes; un cas de compression de la moëlle dorsale avec abolition des réflexes. Journ. de Neurologie, 1897.

Van Gehuchten, La dissociation syringomyélique de la sensibilité dans les compressions et les traumatismes de la moëlle épinière et son explication physiologique. Semaine Médicale, 1899, p. 113, 114.

Grasset, La dissociation dite syringomyélique des sensibilités. Les Cliniques. Montpellier, 1899. 
de Goyon, J., Etude expérimentale et clinique de la conduction sensitive dans la moëlle épinière. Thèse de Bordeaux. Impr. P. Cassignol, 1903.

Hanot et Meunier. Gomme syphilitique double de la moëlle épinière ayant: déterminé un syndrôme de Brown-Séquard bilatéral avec dissociation syringomyélique. Nouvelle Iconograpbie de la Salpetrière, 1896, mars et avril, p. 49.

Herzen, A., Ueber die Spaltung des Temperatursinnes in 2 gesonderte Sinne. Pflügers's Archiv f. Physiologie, 1886, Bd. 38.

Herzen, Quelques points litigieux de physiologie et de pathologie nerveuse. Revue médicale de la Suisse romande. Janvier 1900.

II igier, Zur Diagnose der Erkrankung des Conus medullaris. Gazeta Lekarska. No. 18, 20 (polnisch). Deutsche Zeitschrift f. Nervenheilk. Bd. IX, H. 3 u. 4.1897.

Kocher, Th., Die Verletzungen der Wirbelsäule zugleich als Beitrag zur Physiologie des menschlichen Rückenmarkes. Mittheilungen aus den Grenzgebieten der Medicin und Chirurgie, 1896, S. 536.

Kopczynski, St., Ein Fall von Brown-Séquard nach Stichverletzung des Rückenmarkes. Demonstration in der Warschaner Aerzte-Gesellschaft am 20. XI. 1900. Pamietnik Towarzystwa Lekarskiego, 1900, H. IV, p. 710 (polnisch).

Lähr, Max, Ueber Störungen der Schmerz- und Temperaturempfindung in Folge von Erkrankungen des Rückenmarkes. Archiv für Psychiatrie, 1896, Bd. XXVIII, H. 3.

v. Leyden, E. und Goldscheider, Die Erkrankungen des Rückenmarkes, 1903, S. $50-56$.

Llyod, J. H., A study of the lesions in a case of trauma of the cervical region of the spinal cord simulating syringomelia. Brain 1898, p. 36 .

Mann, J., Klinische und anatomische Beiträge zur Lehre von- der spinalen Hemiplegie. Deutsche Zeitschrift für Nervenheilkunde. 1897, Bd. 10.

Mai, Ernst, Ueber gekreuzte Lähmung des Kältesinnes. Beitrag zur Physiologie der Hauptsinnesbahnen. Archiv für Psych., 1904. Bd. XXXVIII, Heft 1.

Marinesco, Sur les paraplégies flasques par compression de la moëlle. Semaine Médicale, 1898, p. 153.

Minor, Beitrag zur Hämatomyelie und Syringomyelie. Neurolog. Centralblatt, 1890, No. 16.

Minor, Centrale Hämatomyelie. Arch. f. Psychiatrie und Nervenkrankheiten. 1892, Bd. XXIV.

Min or, Klinische Beobachtungen übet centrale Hämatomyelie. Arch. f. Psych. u. Nervenheilk., 1896, Bd. XXVII.

Minor, Recherches cliniques et anatomiques sur les affections traumatiques de la moëlle suivies d'hématomyélie centrale et de deformations cavitaires centrales. Semaine Médicale, 1897, p. 347. 
Hinor, Syringomyelitische Dissociation der Sensibilität bei transversalen Myelitiden. Neurol. Centralblatt, 1898.

Mott, Results of hemisection of the spinal cord in monkeys. Philosoph. Transactions, 1891.

Mott, F., Hemisections made at different levels in the dorsal region of the monkey. Journ. of Physiol., XII, 2, p. 111.

Mott, Exper. enquiry upon the afferents tracts. Brain, XVIII, p. 1, 1895.

Müller, W., Beiträge zur patholog. Anatomie und Physiologie des Rückenmarkes. Leipzig 1871.

Oppenheim, Lehrbuch der Nervenkrankenheiten. 1902, S. 620.

Petrén, K., Kliniska studier öfter akut nyelit och ryggmärgssyfilis, jämte et bidrag till frägen om förloppet of hudsinnenas banor liom ryggmärgen. Hygiea, 1901, p. 232. Ref. von Berger im Neurolog. Centralblatt, 1903, p. 538 .

Petrén, Karl, Ein Beitrag zur Frage der Hautsinnesbahnen im Rückenmark. Skandin. Arch. f. Physiol., Bd. 13, H. 1 u. 2. 1902.

Pi.ck, Neurolog. Centralblatt, 1898, No. 12.

Piltz, J., Contribution à l'étude de la dissociation de la sensibilité douloureuse et thermique dans les cas de traumatisme et d'affection de la moëlle épinière. Thèse de doctorat. Lausanne 1904.

Piltz, J., Ein Beitrag zur Kenntniss der Dissociation der Temperatur- und Schmerzempfindung bei Verletzungen und Erkranliungen des Rückenmarkes. (Vorläufige Mittheilung.) Neurologisches Centralblatt, 1905, No. 6.

Pribytroff,:E., und N. Versiloff, Ein Fall von Hämatomyelia centralis. Bericht der Moskauer Gesellschaft der Neurologen und Irrenärzte. Neurolog. Centralblatt, 1898, No. 2, p. 91.

Raymond, Syndrôme de Brown-Séquard d'origine probablement syringomyélique. Le Progrès Médical, 1895.

Raymond, Sur un cas d'hémisection traumatique de la moëlle. Nouvelle Iconographie de la Salpetrière, 1897.

$R \oplus$ inhardt, Ein Fall von halbseitiger Verletzung des Rückenmarkes. Deutsche Zeitsch. f: Chirurgie. Bd. 47, H. 1. 1897.

v. Reusz, Zur Kenntniss der Halbseitenläsion des Rückenmarkes. Berl. klin. Wochenschr., 1898, No. 38 , S. 836.

Ross, J., On the seg. distrib. of sensory disorders. Brain, 1888, p. 333.

Rossolimo, Thermoanästhesie und Analgesie als Symptome von Herderkrankung des Hirnstammes. Deutsche Zeitschr. f. Nervenheilk., 1903, Bd. 23, S. 243. Jahresbericht der Neurologie u. Psych., 1903, S. 383. Nourolog. Centralblatt, 1903, S. 487.

Schiff, M., Lehrbuch der Physiologie des Nervensystems. 1858-59.

Schlesinger, H., Wiener physiol. Klub. Sitzung vom 26. März 1895. Neurolog. Centralblatt, 1895, S. 751.

Schlesinger, Beiträge zur Klinik der Rückenmarks- und Wirbeltumoren. Jena, 1898.

Schittenhelm, Ueber einen Fall von Stichverletzung des Rückenmarkes 
Zum Studium der Dissociation der Temperatur- u. Schmerzempfindung. 1007

(Brown-Séquard'sche Lähmung) mit besonderer Berücksichtigung des Localisationsvermögens. Deutsche Zeitschr. f. Nervenbeilk., 1902, XXII. Ref. im Neurol. Centralbl., 1903, S. 77.

Sherrington, Experiments in examination of the peripherial distribution of the fibres of the posterior roots of some spinal nerves. Philosoph. Transact. of the Royal Soc. of London, CLXXXVII, p. 164; 1896.

Sklodowski, Ein Fall von Brown-Séquard'scher Lähmung. Gazeta Lekarska, 1901 (polnisch).

Sottas, J., Deux cas d'hémiplégie spinale avec hémianaesthesie croisée. Revue de méd., XIII, 1893.

Starr, Allen, Local anaesthesia as a guide in the diagnosis of lesions of the lower spinal cord. Aneric. Journ. of med. sc. 1892. Citirt nach Kooher.

Starr, Allen, Local anaesthesia as a guide in the diagnosis of lesions of the apper portion of the spinal cord. Brain, XVII, 1894, p. 481.

Starr, Allen; A contribution to the subject of tumors of the spinal cord, with rem. upon their diagn. etc. Americ. Journ. of med. sc., 1895, p. 613. Strümpell, Archiv f. klin. Medicin. XXVIII, H. 1.

Teljatnik, Zur Frage über die Wärme- und Kältenerven. Revue der Psychiatrie (russisch), 1900, No. 7. Jahresbericht der Neurologie u. Psych., 1901, p. 265.

Thorburn, The sens. distribat. of spin. nerv. Brain, XVI, 1893, p. 355.

Tumpowski, Medyeyna (polnisch), 1898. No. 13.

Turner, On hemilesion of the spinal cord. Brain, XIV, 1891, p. 496.

Vines, Despe dissociatiunea siringomielica in diferitele afectiuni ale maduvei spinarei cu aplicatiuni speciale la mielita. Romania medicala, 1898.

Wallenberg, Ad., Acute Bulbäraffection. Arch. f. Psych., Bd. XXVII, H. 2, 1893.

Wallenberg, Anat. Befund bei ete. Arch. f. Psych. Bd. XXXIV, H. 3, 1900.

\section{Nachtrag.}

Seit dem Erscheinen meiner vorläufigen Mitheilung im Neurologischen Centralblatt, 1905, No. 6, hat St. Kopczynski in der Gazeta lekarska 1906 (polnisch) zwei Fälle von Brown-Séquard'scher Lähmung traumatischen Ursprungs beschrieben, in welchen er meine Beobachungen vollkommen bestätigt hat.

Ausserdem ist noch vor ein Paar Monaten eine neue physiologischanatomische Arbeit von Bertholet (Les vois de la sensibilité dolorifique et calorifique dans la moelle. Le Nevraxe, Vol. VII, fase. 3) er- 
1008 Prof. Dr. J. Piltz, Zum Stud. d. Diss. d. Temp.- u. Schmerzempfind.

schienen. Auf Grund seiner experimentellen bei Katzen und Hunden ausgeführten Untersuchungen kommt dieser zu folgenden Schlüssen:

I. Die Schmerz- und Wärme-Empfindungen werden nicht in der grauen Substanz hirnwärts fortgeleitet.

Die graue Substanz stellt somit nicbt das Leitungsorgan für diese Empfindungsqualitäten dar.

II. Die Schmerz- und Wärmeempfindungen werden in den Seitensträngen hirnwärts geleitet.

III. Eine laterale Halbseitenläsion des R. ruft bei der Katze sowohl wie beim Hunde eine bilaterale aufsteigende Degeneration der Seitenstränge hervor, welche jedoch auf der gegenüberliegenden Seite stälker ausgesprochen ist, als auf der Seite der Läsion.

IV. Die Kleinhirnseitenstrangbahn scheint bei der Leitung dieser Empfindungsqualitäten keine unentbehrliche Rolle zu spielen.

V. Die Leitung der Schmerz- und Wärme-Empfindungen scheint vielmehr in der vom Gowers'schen Strang eingenommenen Partie des Seitenstrangs stattzufinden.

Krakau den 26. Juni 1906.

Piltz. 